\title{
Effect of Four Manufacturing Techniques (Casting, Laser Directed Energy Deposition, Milling and Selective Laser Melting) on Microstructural, Mechanical and Electrochemical Properties of $\mathrm{Co}-\mathrm{Cr}$ Dental Alloys, Before and After PFM Firing Process
}

\author{
Óscar Barro 1,2® , Felipe Arias-González ${ }^{3}$, Fernando Lusquiños ${ }^{1,4}$, Rafael Comesaña 1,5, \\ Jesús del Val ${ }^{1}$, Antonio Riveiro ${ }^{1,5}$ (D) Aida Badaoui ${ }^{5}$, Félix Gómez-Baño ${ }^{2}$ and Juan Pou ${ }^{1,4, *(D)}$ \\ 1 LaserOn Research Group, School of Engineering, University of Vigo, Lagoas-Marcosende, E-36310 Vigo, \\ Spain; obarro@uvigo.es (Ó.B.); flusqui@uvigo.es (F.L.); racomesana@uvigo.es (R.C.); \\ jesusdv@uvigo.es (J.d.V.); ariveiro@uvigo.es (A.R.) \\ 2 Corus-Fegoba, C/San Jorge 18, E-15002 A Coruña, Spain; felix.gomez@corusdental.com \\ 3 School of Dentistry, Universitat Internacional de Catalunya, E-08195 Barcelona, Spain; farias@uic.es \\ 4 Galicia Sur Health Research Institute (IIS Galicia Sur). SERGAS-UVIGO, E-36310 Vigo, Spain \\ 5 Materials Engineering, Applied Mechanics and Construction Department, University of Vigo, EEI, \\ Lagoas-Marcosende, E-36310 Vigo, Spain; aida@uvigo.es \\ * Correspondence: jpou@uvigo.es; Tel.: +34-986-812-216
}

Received: 18 August 2020; Accepted: 25 September 2020; Published: 27 September 2020

\begin{abstract}
The objective of this study was to compare four manufacturing processes of Co-Cr dental alloys: casting (CAST), computer aided design/computer aided manufacturing (CAD/CAM) milling (MILL), selective laser melting (SLM), and laser directed energy deposition (LDED). Comparison included microstructural, mechanical, and electrochemical analyses. Half of the samples obtained were heat treated to simulate the porcelain fused to metal (PFM) firing process, and the metal real state in an oral environment. Co-Cr dental alloys manufactured via casting, LDED, milling, and SLM techniques presented evident differences in their mechanical properties. However, their electrochemical performances were similar, with high resistance to corrosion in artificial saliva, in both aerated and deaerated media (corrosion rate under 4 microns per year). LDED and milling materials showed the highest modulus of toughness, and gave improved results in comparison with CAST and SLM techniques $(p<0.05)$. The LDED process could be implemented in the manufacturing of the restorative dental industry, with a high overall performance, competing directly with the best quality techniques, and reducing their disadvantages.
\end{abstract}

Keywords: Co-Cr alloy; laser directed energy deposition (LDED); microstructure; mechanical properties; corrosion behavior; additive manufacturing; dental restorations; casting; milling; selective laser melting (SLM)

\section{Introduction}

Dental restorations have been widely employed throughout the last 100 years. Historically, the most employed materials were gold and its alloys [1]. However, the high value of this metal led to the use of other non-precious metallic alloys like $\mathrm{Co}-\mathrm{Cr}$ or Ni-Cr. However, Ni-based ones are progressively disappearing due to their toxicity [2]. That is why $\mathrm{Co}-\mathrm{Cr}$ alloys are nowadays the predominant preference in the dental restoration industry, thanks to their improved biocompatibility [3] and their better behavior against corrosion [4]. 
Cobalt is characterized as having two crystallographic phases: the $\varepsilon$ hexagonal closed packed (HCP), stable at ambient temperature (up to $417^{\circ} \mathrm{C}$ ), and the $\gamma$ face centered cubic (FCC) phase, metastable from $417^{\circ} \mathrm{C}$ until melting temperature (around $1493{ }^{\circ} \mathrm{C}$ ) [5]. These two phases usually appear together at ambient temperature due to their similar stacking fault energies [6,7]. In addition, the presence of the $\gamma$-FCC phase at ambient temperature is associated with yield strength increment, fatigue resistance, and the ability to absorb stresses through transformation of the structure to $\varepsilon$-HCP [5]. Therefore, efforts to achieve a higher quantity of $\gamma$-FCC in Co parts have been taken over time, including varying the addition of alloying elements as well as grain size, influential factors in phase stability [8].

Co based alloys have been widely used in different fields such as the aeronautical, the petrochemical, or the medical [5]. In dentistry, as well as in the implant field, the alloying elements employed have as a principal target the strengthening of the alloys. Cr improves the mechanical properties of Co alloys as solute and improves the resistance to corrosion $[9,10]$. It also improves cobalt alloys biocompatibility, thanks to the passivation of its oxide layer [5], this being the reason why it is usually the main alloying element. W or Mo also improve the strength of the matrix [7], increasing mechanical performance as well as corrosion resistance [5]. The phase stability is also influenced by the alloying elements, classified into $\gamma$-stabilizers, like W [11] or Fe [5], or $\varepsilon$-stabilizers, like Mo [5] or Cr [7].

The mechanical properties of Co-Cr alloys greatly depend on their precipitation behavior [12]. In low carbon content $\mathrm{Co}-\mathrm{Cr}$ alloys, such as dental alloys, precipitates are usually $\sigma$ and laves intermetallic phases [13], instead of the typical $\mathrm{M}_{12} \mathrm{C}$ and $\mathrm{M}_{23} \mathrm{C}_{6}$ carbides that appear in high carbon content alloys, where the reaction $\sigma+\mathrm{C}=\mathrm{M}_{23} \mathrm{C}_{6}+\mathrm{M}_{12} \mathrm{C}$ takes place [14].

In the past few years $\mathrm{Co}-\mathrm{Cr}$ dental alloys have been under continuous development aiming at improving and studying mechanical (such as elastic modulus, yield strength, or ultimate tensile strength) [15,16] and electrochemical properties (corrosion resistance) [17,18]. Moreover, other investigations such as the machinability of these dental alloys [19], their interaction with ceramics used for dental restorations [20] and the effects of cyclic heat treatments [21] have also been performed.

The manufacturing techniques related to dental restorations for porcelain fused to metal (PFM) Co-Cr alloys have also evolved during the last few decades. The traditional casting processes were widely employed until the appearance of other techniques, affecting even the casting process itself, changing from the manual wax design to CAD/CAM machined disks.

The CAD/CAM of milling disks technology allows an improvement in the precision of the final parts as well as the homogeneity of the material, and is the technique of choice today. However, milling disks have some limitations such as disk size or material efficiency.

That is why in the past few years, the selective laser melting technique (SLM) has been implemented in the dental industry. SLM allows an increment of material efficiency as well as the free form manufacturing of parts [22]. SLM (Figure 1A) is an additive manufacturing technique of the family of the powder bed fusion (PBF) processes that employs a laser as the energy source. The laser melts the material powder and generates a part, one layer at a time. The powder material is preplaced layer by layer on the whole bed surface, where only the zones irradiated by the laser beam are melted, generating a solid object. SLM has been widely reviewed in the literature [22,23] and compared with other additive manufacturing techniques [24]. Today, SLM is a manufacturing technology widely employed in the dental industry, just as much as casting or milling. Additionally, a two-step manufacturing methodology is also employed with this technique. After additive manufacturing, the machining of the abutment faces (the zones which interact with the dental implant) is carried out. This two-step methodology puts together the freeform capabilities of the SLM and the high precision of the milling processes [25]. 


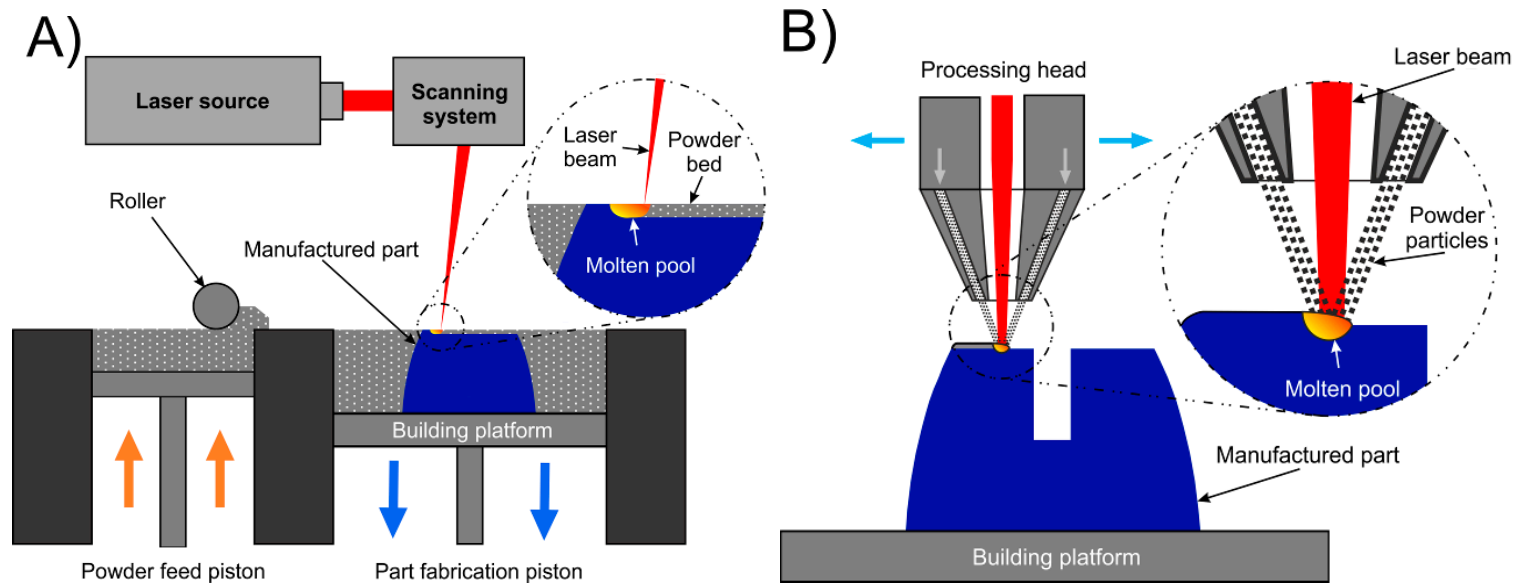

Figure 1. Outline of the selective laser melting (SLM) (A) and the directed laser deposition (LDED) (B) manufacturing techniques.

Laser directed energy deposition (LDED, Figure 1B) is an additive manufacturing technique of the family of directed energy deposition (DED) processes that employ a laser as an energy source. The interaction of the laser beam with the sacrificial substrate, generates a molten pool that grows by means of the injection of material (usually in powder form fluidized by a carrier gas [26]). The relative movement between the laser processing head and the workpiece allows, by overlapping the clad tracks, the deposition of the material, and, by the addition of subsequent layers, the final part is obtained.

The LDED process generates a good metallurgical bonding between layers, with reduced porosity, as well as high material deposition efficiency rates $[27,28]$. LDED was firstly employed in the generation of different coatings: Ni alloys [28], titanium [29], or Co-based alloys [30], even at microscopic scale [31]. In the recent years, this technique has started to be employed in the additive manufacturing of functional parts using metals [32]. Additionally, a method for producing parts made of ceramic biomaterials has been developed [33]. The high versatility of this technique is directly related to its processing parameters [34]. The final microstructure of the generated material can be controlled by an adequate tuning of the processing parameters [35]. This is of major importance in Co-Cr dental alloys, where the final microstructure has a great influence on the overall behavior of the material.

LDED is a near net shape process. The two-step manufacturing methodology employed with the SLM technique can also be applied to LDED to achieve the small details and tolerance requirements of dental prostheses [36].

Moreover, LDED can have the capability of generating dental restorations that merge the benefits of freeform generation and material efficiency of additive manufacturing processes (like SLM), and the high performance of the materials employed in CAD/CAM milling techniques.

LDED has been used previously for producing $6 \mathrm{~mm}$ [30] or $10 \mathrm{~mm}$ [37] thick CoCrMo deposits on metal orthopedic applications, producing sound metallurgical material. LDED manufacturing of load bearing implants, such as hip implants, has also been studied. It has been found that by tuning the process parameters, pore characteristics and mechanical properties can be adjusted to the requirements of specific implants, which could even mimic the hybrid structure of a real bone [38].

Previous works have given the right clues to applying the LDED technique to produce prosthetic structures tailored to the anatomy of each patient. However, it is necessary to first assure that the technique complies with the existing ISO standards for dental materials.

Therefore, the main objective of this paper is to provide a quantitative experimental study on the manufacturing techniques currently used for the production of prosthetic dental restorations made out of Co-Cr alloys, and the LDED technique, a novel additive manufacturing alternative in the dental field. This comparison comprised the typical manufacturing techniques, such as casting or CAD/CAM milling processes, and modern techniques, such as SLM (already implemented in the dental industry) and LDED. All of this was done through a multidisciplinary approach, including microstructural, 
mechanical, and electrochemical analyses, following the ISO standards that allow the qualification of materials for prosthetic dental applications.

\section{Materials and Methods}

\subsection{Specimen Generation}

Four different manufacturing techniques (CAST, LDED, MILL, SLM) were employed to manufacture the specimens using Co-Cr dental alloys. Half of these specimens (except for the electrochemical ones) were heat treated following the veneering processes, detailed in Section 2.2, in order to simulate the porcelain fused to metal (PFM) behavior in an oral environment. Composition of the Co-Cr alloys used in the present study are collated in Table 1. These alloys present slightly different compositions, which can lead to some influence on the results.

Table 1. Summary of the tested alloys composition, provided by the manufacturers.

\begin{tabular}{|c|c|c|c|c|c|c|c|c|c|c|}
\hline Brand Name & Manufacturer & Co & $\mathrm{Cr}$ & W & Mo & $\mathrm{Si}$ & Mn & $\mathrm{Fe}$ & ISO 22674 Type & $\begin{array}{l}\text { Used in } \\
\text { Technique }\end{array}$ \\
\hline Heraenium Pw & $\begin{array}{c}\text { Kulzer GmbH, } \\
\text { Germany } \\
\text { S and S }\end{array}$ & 55.2 & 24 & 15 & 4 & 1 & 0.8 & 4 & 4 & CAST \\
\hline $\begin{array}{c}\text { Starbond Easy } \\
\text { Powder } 30+\end{array}$ & $\begin{array}{c}\text { Scheftner } \\
\text { GmbH, } \\
\text { Germany }\end{array}$ & 61 & 27.5 & 8.5 & - & 1.6 & $<1$ & $<1$ & 4 & LDED \\
\hline Kera ${ }^{\circledR}$-Disc & $\begin{array}{c}\text { Eisenbacher } \\
\text { Dentalwaren } \\
\text { ED GmbH, } \\
\text { Germany }\end{array}$ & 61.65 & 27.75 & 8.45 & - & - & 0.25 & 0.2 & 4 & MILL \\
\hline $\begin{array}{c}\text { EOS } \\
\text { CobaltChrome } \\
\text { SP2 }\end{array}$ & $\begin{array}{c}\text { EOS GmbH, } \\
\text { Germany }\end{array}$ & 63.8 & 24.7 & 5.4 & 5.1 & 1 & 0.1 & 0.5 & 4 & SLM \\
\hline
\end{tabular}

The casting (CAST) specimens were fabricated by first machining the geometries into a wax disc, before embedding them with phosphate-bonded investment. The mold was cast with Heraenium $\mathrm{Pw}$ alloy using a motor-driven centrifugal casting machine (Minicast, Ugin'dentaire Siège Social, Seyssinet-Pariset, France) and melted with a casting torch following the manufacturer's recommendations.

The laser directed energy deposition (LDED) specimens were generated using a proprietary LDED manufacturing device (LaserOn Research group, Vigo, Spain). This system is composed of a 1600 $\mathrm{W}$ high power diode laser as power source to generate the molten pool in a $\mathrm{Co}-\mathrm{Cr}$ building plate, a commercial pneumatic powder feeder, a coaxial injection powder system (a coaxial laser head similar to commercial ones such as Precitec YC52), and a CNC (Computer Numerical Control) controlled 3-axis positioning system enclosed in a controlled-ambient inert chamber, using argon as a protective atmosphere. Commercial Co-Cr powder (Starbond Easy Powder 30+), with a particle size between 10 and $70 \mu \mathrm{m}$, was used as precursor material. After that, the near net shape specimens were separated from the building plates and machined until final dimensions in a milling CAD/CAM system (DT2, Dyamach Italia, Mussolente, Italy). The angle between building and tensile directions of the tensile specimens was $90^{\circ}$.

The milling (MILL) specimens were machined from commercial Co-Cr Kera ${ }^{\circledR}$-Disc dental discs using a CAD/CAM milling machine (DT2, Dyamach Italia, Mussolente, Italy) that employed solid carbide cutting tools. This milling process was only required for tensile test samples in order to comply with the tolerance dimensions of the ISO 22674:2016 standard. The angle between axial disc direction and tensile directions of tensile specimens was $90^{\circ}$.

Selective laser melting (SLM) specimens were generated using an EOS M 270 (EOS GmbH, Krailling, Germany) machine, with a $400 \mathrm{~W}$ fiber laser as power source and under an inert atmosphere of nitrogen. The material employed was Co-Cr EOS SP2 powder. The angle between building and tensile directions of tensile specimens was also $90^{\circ}$, as in the LDED alloy. 


\subsection{PFM Simulation}

For the porcelain fused to metal firing simulation (PFM firing simulation), half of the specimens were thermally treated to simulate the thermal effects of the veneering processes (except for the electrochemical ones that were all treated). This process is composed of two opaquer cycles, one dentin cycle, and finally one glazing process; all according to the manufacturer's instructions detailed in Table 2.

Table 2. Summary of the porcelain fused to metal (PFM) veneering procedure used in this study.

\begin{tabular}{ccccccc}
\hline $\begin{array}{c}\text { Firing } \\
\text { Process }\end{array}$ & $\begin{array}{c}\text { Preheating } \\
\text { Temperature } \\
\left({ }^{\circ} \mathbf{C}\right)\end{array}$ & $\begin{array}{c}\text { Drying Time } \\
(\mathbf{m i n})\end{array}$ & $\begin{array}{c}\text { Raise of } \\
\text { Temperature }\left({ }^{\circ} \mathbf{C} / \mathbf{m i n}\right)\end{array}$ & $\begin{array}{c}\text { Vacuum } \\
\text { Temperature Holding Time } \\
(\mathbf{m i n})\end{array}$ & $\begin{array}{c}\text { Total Approx. } \\
\text { Time (min) }\end{array}$ \\
\hline Bonding & 650 & 6 & 55 & Yes & 980 & 1 \\
Opaquer 1 & 550 & 6 & 80 & Yes & 940 & 1 \\
Opaquer 2 & 550 & 6 & 80 & Yes & 940 & 1 \\
Dentin 1 & 580 & 6 & 55 & Yes & 900 & 1 \\
Dentin 2 & 580 & 6 & 55 & Yes & 900 & 1 \\
Glaze & 600 & 2 & 55 & Yes & 860 & 15 \\
\hline
\end{tabular}

\subsection{Microstructural Characterization}

\subsubsection{SEM-EDS-EBSD Analysis}

For microstructural analysis, one specimen of each process, (that gives eight samples corresponding to the 4 different techniques, before and after PFM firing simulation) were examined using a scanning electron microscope (SEM, Philips XL30, FEI Technologies Inc., Hillsboro, OR, USA) coupled with an energy-dispersive X-ray spectroscopy (EDS) unit (EDAX PV9760, EDAX Inc, Mahwah, NJ, USA). All samples $(6 \mathrm{~mm} \times 6 \mathrm{~mm} \times 6 \mathrm{~mm})$ were cut in half, embedded in resin and polished using colloidal silica $(0.04 \mu \mathrm{m})$ suspension as the final step. The polished surfaces were imaged by means of backscattered electron detection (BSE) employing $20 \mathrm{kV}$ of accelerating voltage and $10 \mathrm{~mm}$ of working distance as main parameters. The elemental composition was determined via EDS under the same working conditions as BSE and $60 \mathrm{~s}$ of acquisition time. Semi-quantitative analysis of the mapping results was generated using ZAF correction. The crystallographic texture was analyzed by electron backscatter diffraction (EBSD) (Oxford HKL Channel 5, Oxford Instruments, Abingdon, UK) detector mounted on a dual-beam FEI HELIOS 600 NanoLab (FEI Technologies Inc., Hillsboro, OR, USA) also providing inverse pole figure (IPF) maps.

\subsubsection{XRD Analysis}

One specimen of each technique, eight in total (CAST, LDED, MILL, and SLM; all before and after PFM firing simulation) were scanned using X-ray diffraction (XRD, Siemens D5000, KS Analytical Systems, Aubrey, TX, USA) over the $30-120^{\circ} 2 \theta$ range $\left(40 \mathrm{kV}, 30 \mathrm{~mA}, 0.05^{\circ}\right.$ step size, $3 \mathrm{~s}$ step time) with monochromated $\mathrm{Cu}-\mathrm{K} \alpha$ radiation $(\lambda=1.54 \AA)$. The samples $(6 \mathrm{~mm} \times 6 \mathrm{~mm} \times 6 \mathrm{~mm})$ were cut in half and ground using 320 grit $\mathrm{SiC}$ paper in order to compare the crystal structure of the materials in samples with similar size of the commercial restorations.

\subsection{Mechanical Characterization}

Tensile mechanical tests were performed in accordance to ISO 22674:2016 standard, being the length of the samples of $42 \mathrm{~mm}$ with $3 \mathrm{~mm}$ of diameter in the evaluation zone. For the tensile test, 24 samples of each technique (CAST, LDED, MILL and SLM; half without and half with PFM firing simulation treatment) were generated. The tensile tests were performed using a tensile test machine (LFV 25, Walter + Bai AG, Löhningen, Switzerland) equipped with an extensometer (3542-010M-020-ST, Epsilon Technology Corporation, Jackson, WY, USA) setting the stroke motion at $1.5 \mathrm{~mm} / \mathrm{min}$ until fracture. After fracture, all samples were joined together, and the distance between marks was measured using an optical microscope equipped with a micrometric positioning table. Additionally, 
the toughness was independently calculated by integrating the stress-strain results of all the tensile tests and, subsequently, statistically treated as the other results obtained.

The Vickers microhardness (according to standard ISO 6507-1:2018) was measured in one specimen of each process $(6 \mathrm{~mm} \times 6 \mathrm{~mm} \times 6 \mathrm{~mm}$ ), eight in total (CAST, LDED, MILL, and SLM; before and after PFM firing simulation) using microindentation (microindenter Shimadzu HMV-G, Shimadzu Corporation, Kyoto, Japan), which applied a load of $1 \mathrm{kp}$ for $10 \mathrm{~s}$ of dwell time. The test was repeated in 5 different zones, and averaged in order to achieve a representative measurement of the entire samples.

The fractographic analysis was performed by analyzing the fracture surfaces of the tensile tests using optical microscopy (SMZ1000, Nikon Metrology, Brighton, MI, USA), and secondary electron imaging in SEM. All samples were carefully placed, the building orientation of the samples being aligned with the vertical axis of the images, in order to assess the possible influence of building direction in the process.

\subsection{Electrochemical Characterization}

The electrochemical tests were performed in accordance with ISO 10271:2011, with samples of cylindrical shape with $25 \mathrm{~mm}$ of diameter and $5 \mathrm{~mm}$ of thickness. Potentiodynamic polarization scans (Autolab PGSTAT302N, Metrohm Autolab B.V., Utrecht, The Netherlands) were conducted using a vertical cell of three electrodes in the presence of artificial saliva (AS).

The AS was prepared by adding $9.0 \mathrm{~g}$ of $\mathrm{NaCl}$ into $950 \mathrm{~mL}$ of water, then the $\mathrm{pH}$ was adjusted to $7.2 \pm 0.1$ with $\mathrm{NaOH}$, adding water until $1000 \mathrm{~mL}$. The reference electrode employed was a saturated calomel electrode (SCE), the samples of each test (surface of $1 \mathrm{~cm}^{2}$ ) were employed as working electrodes, and a platinum mesh was selected as counter electrode.

Two types of electrochemical tests were performed, one in aired medium and the other in deaerated medium (argon), in order to simulate the small gaps in the oral medium. Therefore, two samples (one for each test) were generated, thermally treated through the PFM firing simulation and ground with 320 grit $\mathrm{SiC}$ to homogenize the surfaces. After that, at least two repetitions of each sample in different zones were made to achieve a more representative measurement.

\subsection{Statistical Analysis}

All raw data were processed using R-project (v.3.6.3, The R Foundation for Statistical Computing, Vienna, Austria) for data analysis and statistical computing of the tests results. Mechanical and electrochemical data were compared using two-way ANOVA followed by the Tukey HSD test (level of significance, alpha $=0.05)$.

\section{Results}

\subsection{Microstructural Analysis}

SEM images obtained from the CAST, LDED, MILL, and SLM samples revealed different microstructures as well as their evolution through the PFM firing simulation (Figure 2). The CAST (Figure 2A) alloy showed a typical dendritic matrix, and an interdendritic segregation with higher atomic weight. The LDED alloy (Figure 2B) showed a columnar grain structure with a very small amount of intergranular segregation, with vertical orientation. The MILL alloy (Figure 2C) was composed of equiaxial grains with vertical intergranular segregation zones, similar to the CAST specimens, probably due to the discs' fabrication method. The SLM alloy (Figure 2D) showed small-sized grains, with a cellular structure and homogenous segregation throughout the whole material, being barely discernible in electronic microscopy. Furthermore, this intergranular segregation had a different growth, depending on the process (Figure 3A). Before PFM firing, a third level of segregation, with more atomic weight, appeared in the CAST and MILL alloys; while in the LDED and SLM this third level did not appear. 


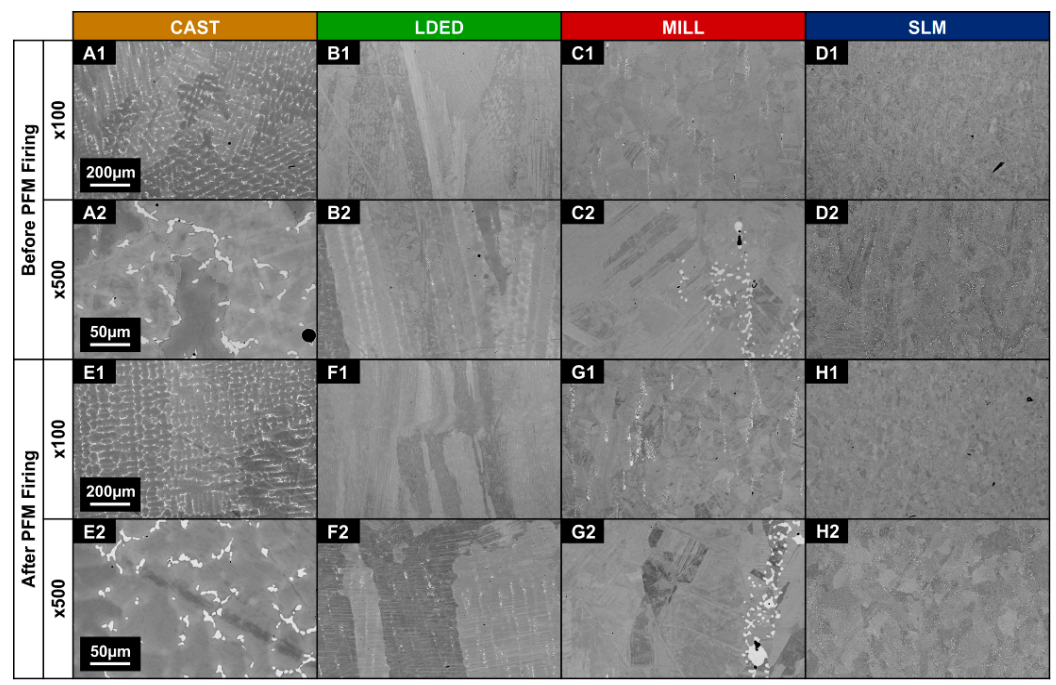

Figure 2. SEM micrographs showing a longitudinal section of each fabrication technique: CAST (A,E), $\operatorname{LDED}(\mathbf{B}, \mathbf{F}), \operatorname{MILL}(\mathbf{C}, \mathbf{G})$ and SLM (D,H); before (A-D) and after $(\mathbf{E}-\mathbf{H})$ PFM firing simulation, at $\times 100(\mathbf{1})$ and $\times 500(2)$ amplification.

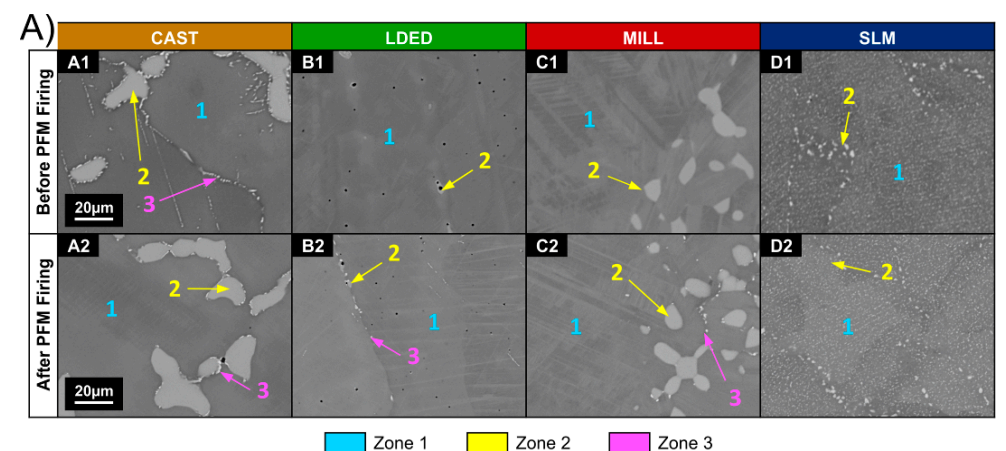

B)

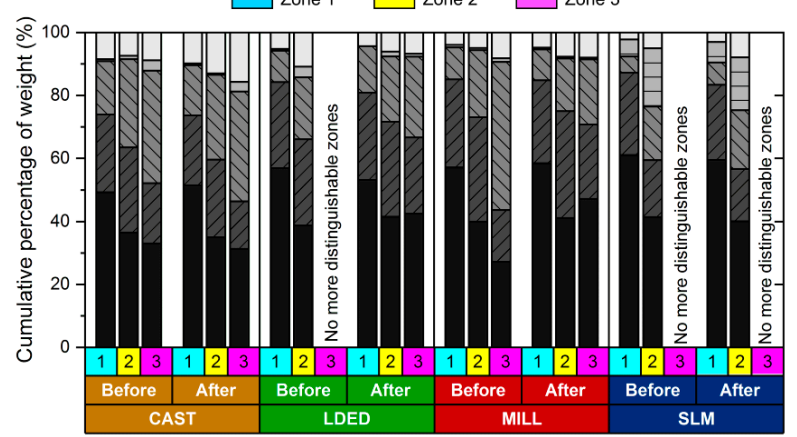

$\square \mathrm{Co} \square \mathrm{cr} \square \mathrm{w} \square \mathrm{Mo} \square \mathrm{si}$, Fe \& others

Figure 3. (A) Representative SEM micrographs of the segregation in each fabrication technique: CAST (A1,A2), LDED (B1,B2), MILL (C1,C2) and SLM (D1,D2). (B) Corresponding energy-dispersive $\mathrm{X}$-ray spectroscopy (EDS) quantification analysis of the matrix 1 and segregation zones 2,3. All of it before and after PFM firing simulation.

The microstructure was also characterized after the PFM firing simulations (Figure 2), in order to assess the influence of the firing cycles on the alloys performance. The CAST alloy (Figure 2E) did not show discernible evolution. The LDED alloy (Figure 2F) showed a low intergranular segregation increment, appearing as a reduced zone of third segregation (Figure 3A,B). The MILL alloy (Figure 2G) also showed an increment of segregation, being more noticeable as the increment of the third zone (Figure 3A,C). Finally, the SLM (Figure 2H) images suggested a grain size refinement. 
In order to identify these segregations, EDS analysis was employed (Figure 3) showing that the segregations were richer in W (CAST, LDED, MILL and SLM) and Mo (CAST and SLM) than the matrix (Figure 3A, number 1), demonstrating a noticeable similarity between techniques (Table 3).

Table 3. Semi-quantitative chemical composition (wt.\%) of the matrix 1 and segregation zones 2,3 determined by EDS. Before and after PFM firing simulation.

\begin{tabular}{cccccccc}
\hline Technique & PFM Firing & Zone & Co & Cr & W & Mo & Si, Fe and Others \\
\hline CAST & Before & 1 & 49.27 & 24.67 & 16.94 & 0.62 & 8.50 \\
CAST & Before & 2 & 36.54 & 26.98 & 28.05 & 1.04 & 7.39 \\
CAST & Before & 3 & 33.06 & 19.12 & 35.74 & 3.24 & 8.84 \\
CAST & After & 1 & 51.44 & 22.22 & 15.93 & 0.56 & 9.84 \\
CAST & After & 2 & 34.95 & 24.69 & 26.87 & 0.54 & 12.95 \\
CAST & After & 3 & 31.27 & 15.11 & 34.92 & 3.01 & 15.69 \\
LDED & Before & 1 & 57.01 & 27.27 & 9.95 & 0.59 & 5.18 \\
LDED & Before & 2 & 38.7 & 27.36 & 19.77 & 3.36 & 10.81 \\
LDED & Before & 3 & - & - & - & - & - \\
LDED & After & 1 & 53.21 & 27.66 & 14.8 & 0 & 4.33 \\
LDED & After & 2 & 41.52 & 30.16 & 20.71 & 1.55 & 6.06 \\
LDED & After & 3 & 42.45 & 24.21 & 25.62 & 1.04 & 6.68 \\
MILL & Before & 1 & 57.14 & 27.98 & 10.21 & 0.73 & 3.94 \\
MILL & Before & 2 & 39.99 & 33.12 & 21.33 & 0.63 & 4.93 \\
MILL & Before & 3 & 27.18 & 16.47 & 47.01 & 1.22 & 8.12 \\
MILL & After & 1 & 58.54 & 26.26 & 9.79 & 0.58 & 4.83 \\
MILL & After & 2 & 41.09 & 33.97 & 16.65 & 0.57 & 7.72 \\
MILL & After & 3 & 47.19 & 23.6 & 20.69 & 0.57 & 7.95 \\
SLM & Before & 1 & 61.09 & 26.17 & 5.15 & 5.40 & 2.19 \\
SLM & Before & 2 & 41.4 & 18.04 & 17.02 & 18.5 & 5.04 \\
SLM & Before & 3 & - & - & - & - & - \\
SLM & After & 1 & 59.57 & 23.8 & 7.13 & 6.50 & 3.01 \\
SLM & After & 2 & 40.09 & 16.59 & 18.65 & 16.84 & 7.83 \\
SLM & After & 3 & - & - & - & - & - \\
\hline
\end{tabular}

Note: Zones 1, 2, and 3 correspond to those indicated in Figure 3.

In terms of crystallography, the XRD analyses show (Figure 4) that the phase composition of the materials was characterized by a combination of the cubic high temperature metastable $\gamma$-FCC and the hexagonal low temperature stable $\varepsilon$-HCP structures in all alloys.

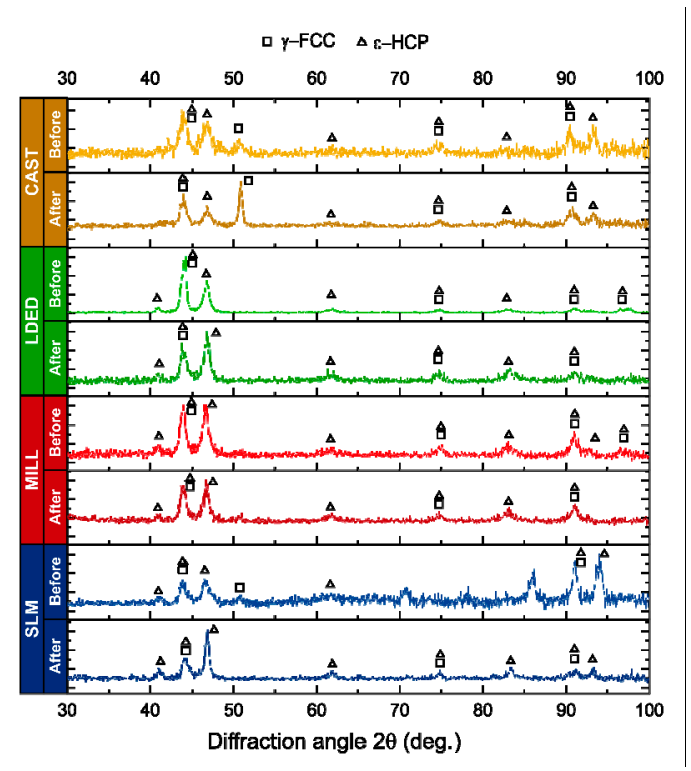

Figure 4. Comparative of X-ray diffraction patterns of all techniques before and after PFM firing. 
EBSD analyses were performed (Figure 5) to quantitatively evaluate the crystallography comparison between fabrication techniques and the evolution of phases. The cast alloy showed a full $\gamma$-FCC structure (Figure 5A1) with no preferred texture (Figure 5A2). LDED samples showed a matrix of big $\gamma$-FCC grains, with small $\varepsilon$-HCP grains before PFM firing (Figure 5B). MILL (Figure 5C) alloy was composed of a homogeneous group of $\gamma$-FCC and $\varepsilon$-HCP grains with no preferential orientation.

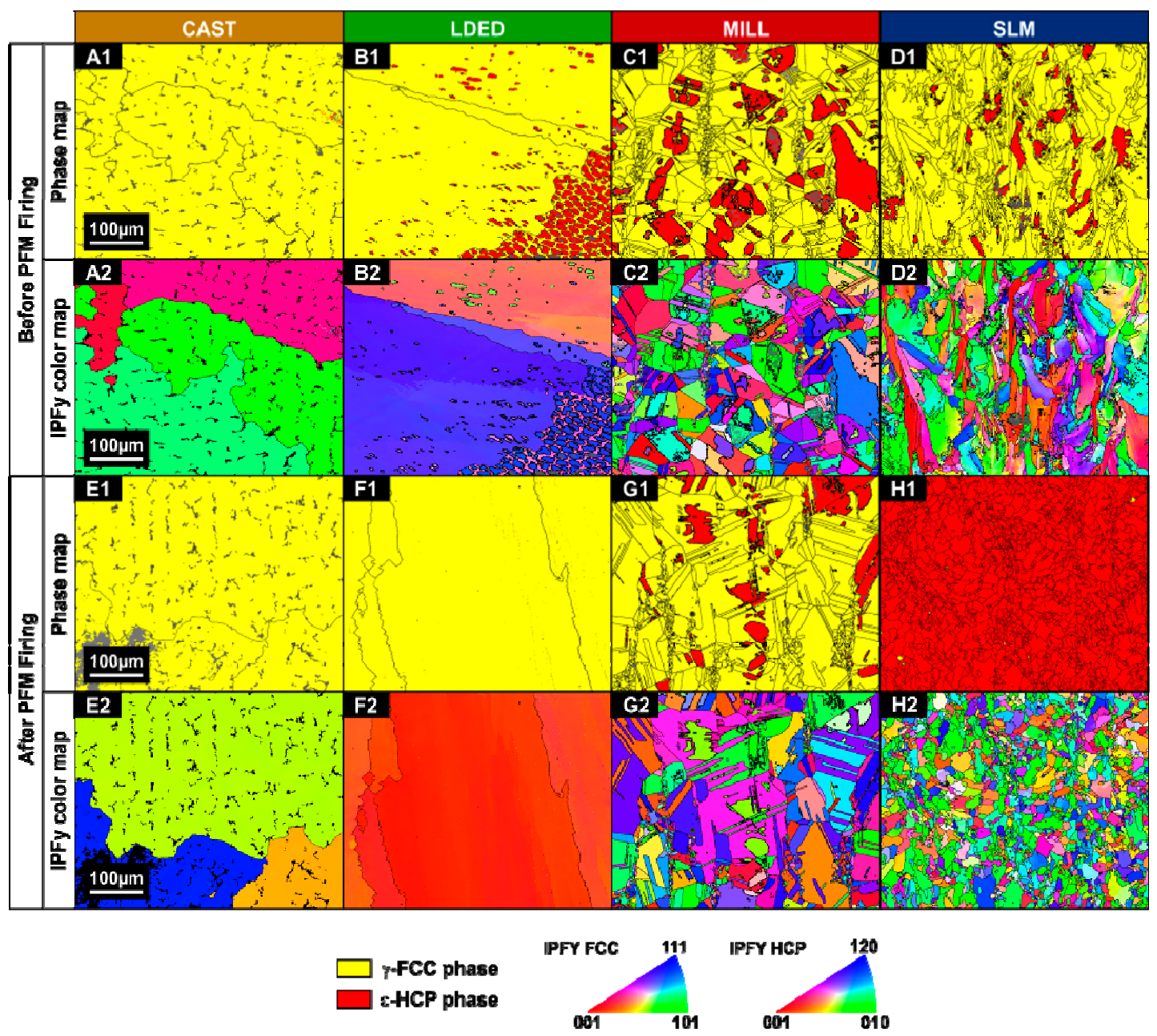

Figure 5. Electron backscatter diffraction (EBSD) phase maps (1) and IPFy (Inverse Pole Figure, $y$ axis) color maps (2) showing a longitudinal section of each fabrication technique, before (A-D) and after (E-H) PFM firing simulation.

However, after the firing, the $\gamma$-FCC phase area fraction increased in LDED (from $89.10 \%$ to $99.70 \%$ of the total area), where only $\gamma$-FCC was found (Figure 5F), and in the MILL material (from $76.94 \%$ to $82.96 \%$ of the total area) (Table 4). In the CAST material, the phase change was negligible due to the small amount of $\varepsilon$-HCP present before the firing process. Finally, the $\gamma$-FCC phase proportion of the SLM material (Figure $5 \mathrm{H}$ ) changed dramatically from $92.71 \%$ to a negligible $0.20 \%$. 
Table 4. Measured area-weighted average grain size and area fraction of the corresponding phases before and after PFM firing simulations of the indexed area in EBSD images. Standard deviation (SD) in parentheses.

\begin{tabular}{|c|c|c|c|c|}
\hline Technique & PFM Firing & Phase & $\begin{array}{c}\text { Area-Weighted } \\
\text { Average Grain } \\
\text { Size }(\mu \mathrm{m})\end{array}$ & $\begin{array}{l}\text { Phase Area } \\
\text { Fraction (\%) }\end{array}$ \\
\hline CAST & Before & $\gamma$-FCC & $371.76(107.84)$ & $99.95 \%$ \\
\hline CAST & Before & $\varepsilon-\mathrm{HCP}$ & $1.10(0.21)$ & $0.05 \%$ \\
\hline CAST & After & $\gamma$-FCC & 337.47 (104.98) & $100.00 \%$ \\
\hline CAST & After & $\varepsilon-\mathrm{HCP}$ & - & $0.00 \%$ \\
\hline LDED & Before & $\gamma$-FCC & $289.13(79.84)$ & $89.10 \%$ \\
\hline LDED & Before & $\varepsilon-\mathrm{HCP}$ & $16.35(14.25)$ & $10.90 \%$ \\
\hline LDED & After & $\gamma$-FCC & 317.54 (108.15) & $100.00 \%$ \\
\hline LDED & After & $\varepsilon-\mathrm{HCP}$ & - & $0.00 \%$ \\
\hline MILL & Before & $\gamma$-FCC & $17.40(9.93)$ & $77.73 \%$ \\
\hline MILL & Before & $\varepsilon-\mathrm{HCP}$ & $27.12(23.97)$ & $22.27 \%$ \\
\hline MILL & After & $\gamma$-FCC & $29.13(19.00)$ & $87.91 \%$ \\
\hline MILL & After & $\varepsilon-\mathrm{HCP}$ & 20.78 (12.89) & $12.09 \%$ \\
\hline SLM & Before & $\gamma$-FCC & $23.84(16.77)$ & $93.05 \%$ \\
\hline SLM & Before & $\varepsilon-\mathrm{HCP}$ & $11.15(6.06)$ & $6.95 \%$ \\
\hline SLM & After & $\gamma$-FCC & $3.62(1.71)$ & $0.20 \%$ \\
\hline SLM & After & $\varepsilon-\mathrm{HCP}$ & $9.90(5.74)$ & $99.80 \%$ \\
\hline
\end{tabular}

\subsection{Mechanical Properties}

The mechanical properties among the different manufacturing processes differed notably. The stress-strain graph (Figure 6) shows a representative test from each manufacturing technique. This graph clearly presents a difference in behavior between SLM and the other techniques (CAST, LDED, and MILL). The curve corresponding to the SLM material indicates an increase in resistance as well as a reduction in ductility. On the other hand, the tests corresponding to the materials obtained by the other techniques, present a similar response but with a different breaking point, having a noticeable variation among the strain at fracture.

A total of six mechanical properties were analyzed in order to quantitatively assess the mechanical properties of the alloys (Table 5). Additionally, a summary of the significance results for mechanical properties are shown in Appendix A (Table A1). The yield strength (Figure 7A) is noticeably higher $(p<0.05)$ in the SLM material as well as its ultimate tensile strength (UTS, Figure 7B), while the LDED and MILL have a similar behavior $(p>0.05)$ followed by the CAST material with a slight reduction of UTS $(p<0.05)$. The Young modulus (Figure 7C) is quite similar among the techniques $(p>0.05)$. The elongation after fracture (Figure 7E) also has significant differences $(p<0.05)$ : the LDED and the MILL specimens showed higher elongation (LDED: 15.57\%, MILL: 15.34\%) in comparison with the SLM material (3.63\%), while the CAST alloy remained in a medium range of elongation $(7.03 \%)$. So as to integrate these properties in one quantitative and comparable characteristic, the modulus of toughness of the materials was collated. As shown in Figure 7D, the LDED and MILL specimens absorbed nearly twice as much energy as the CAST and SLM materials, until they became fractured. The microhardness is also shown in Figure 7F, where the SLM also presents a higher Vickers hardness $(p<0.05)$. 


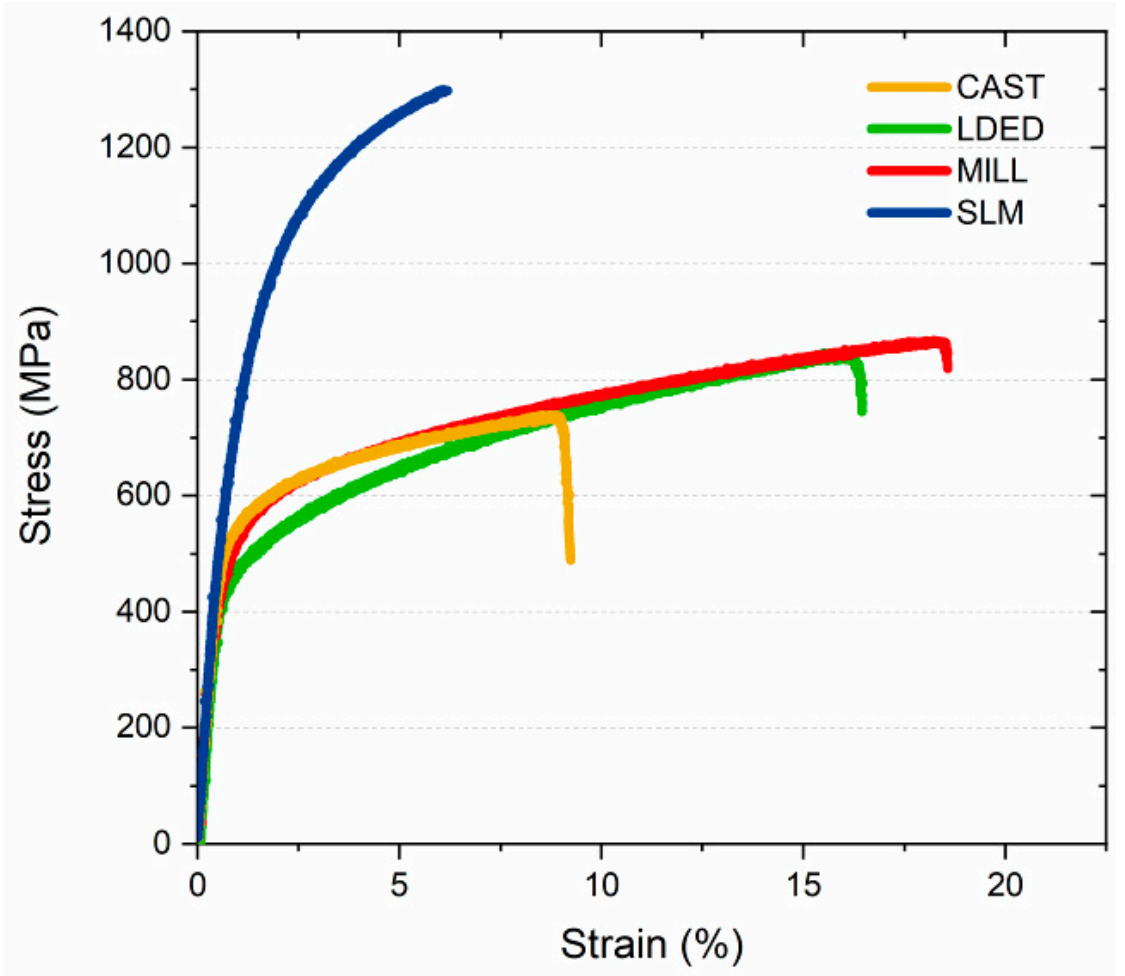

Figure 6. Representative stress-strain curves of the tensile tests among different techniques before PFM firing.

Table 5. Numerical results of mechanical properties of the different techniques evaluated before and after PFM firing simulation. Standard deviation (SD) in parentheses.

\begin{tabular}{|c|c|c|c|c|c|c|c|}
\hline Technique & $\begin{array}{l}\text { PFM } \\
\text { Firing }\end{array}$ & $\begin{array}{c}\text { Yield } \\
\text { Strength } \\
0.2 \% \\
(\mathrm{MPa})\end{array}$ & $\begin{array}{c}\text { Ultimate } \\
\text { Tensile } \\
\text { Strength } \\
\text { (MPa) }\end{array}$ & $\begin{array}{l}\text { Young } \\
\text { Modulus } \\
\text { (GPa) }\end{array}$ & $\begin{array}{c}\text { Modulus of } \\
\text { Toughness } \\
\left(\mathrm{MJ} / \mathrm{m}^{3}\right)\end{array}$ & $\begin{array}{c}\text { Enlongati-on } \\
\text { After Fracture } \\
(\%)\end{array}$ & $\begin{array}{c}\text { Microhardness } \\
\text { (HV) }\end{array}$ \\
\hline CAST & Before & $506(57)$ & $697(52)$ & 229 (17) & 57 (10.9) & $7.0(1.31)$ & $304(5)$ \\
\hline CAST & After & 505 (15) & $690(30)$ & $220(7)$ & 49 (11.8) & $8.6(1.47)$ & $296(16)$ \\
\hline LDED & Before & 425 (43) & $842(41)$ & 223 (13) & $113(16.6)$ & $15.3(1.7)$ & $308(5)$ \\
\hline MILL & After & $428(34)$ & $829(24)$ & $242(4)$ & $112(12.3)$ & $13.2(0.59)$ & 269 (23) \\
\hline SLM & Before & $679(88)$ & $1296(17)$ & $236(16)$ & $62(4.0)$ & $3.6(0.28)$ & 440 (17) \\
\hline SLM & After & 965 (37) & $1548(24)$ & $247(5)$ & 59 (6.3) & $2.1(0.52)$ & $529(10)$ \\
\hline
\end{tabular}

The results obtained show that all the materials comply with the standard ISO 22674 requirements for Type 4 material (yield strength: $360 \mathrm{MPa}$, elongation after fracture: $2 \%$ ).

The fractographs (Figure 8) verify the results of the mechanical analysis. The SLM specimens present a cleavage fracture (where the crack propagation from the upper point can be observed), being the fractured surface perpendicular to the tensile stress axis of the tensile tests. Even though this fracture has a macroscopic brittle behavior, it also presents small dimples at microscopic level (Figure 8D2). The presence of these dimples suggests a cleavage crack initiation in grain boundary segregations, caused by plastic deformation of the grains [39].

The CAST, LDED, and MILL specimens each have a fibrous topography, caused by a higher plastic deformation until fracture, as well as some degree of section necking. Additionally, the fractographs suggest some influence of the building direction. 

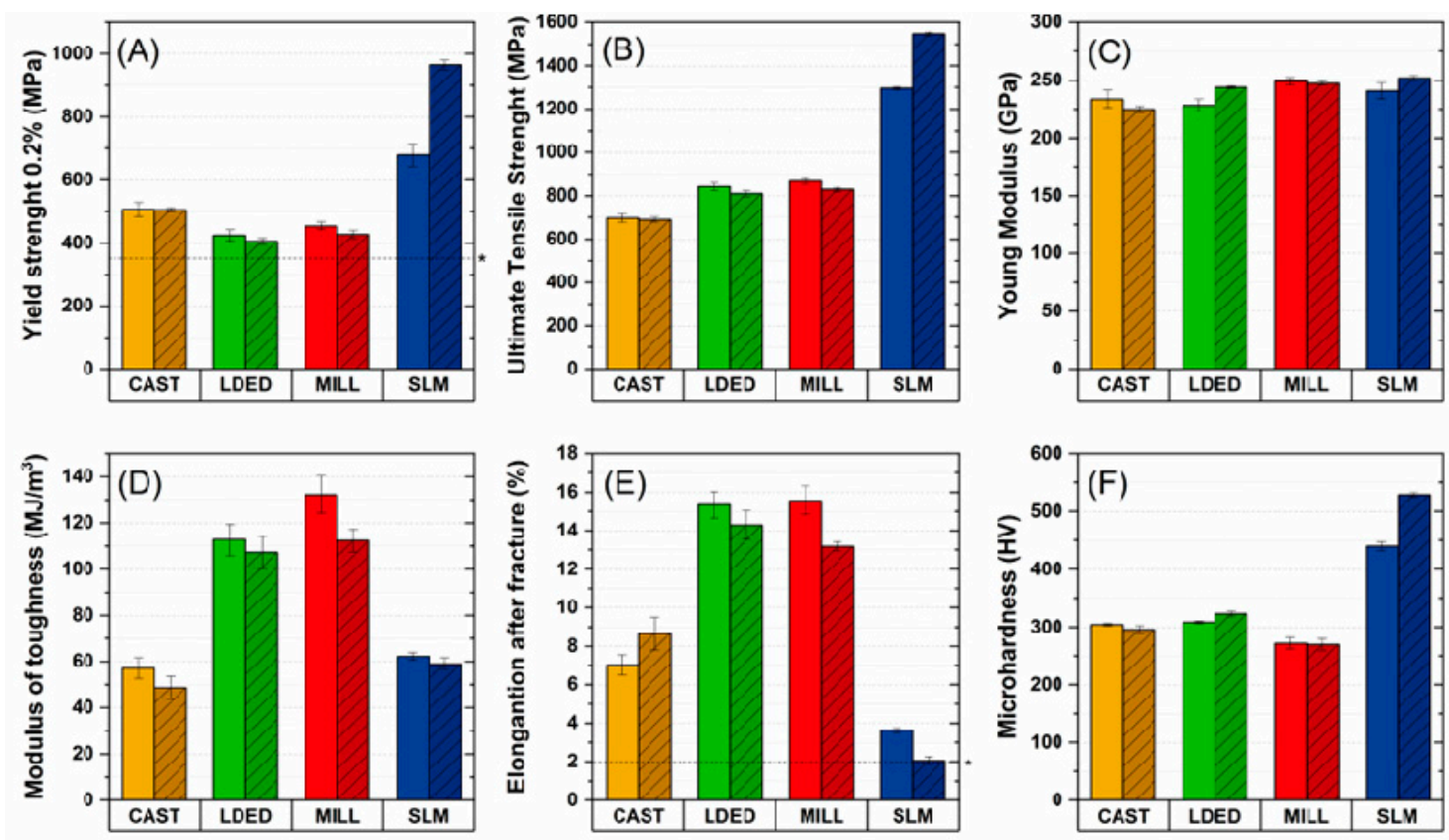

Figure 7. Mechanical properties of the different techniques evaluated before and after PFM firing simulation: yield strength (A), ultimate tensile strength (B), Young modulus (C), modulus of toughness (D), elongation after fracture (E), and microhardness (F). Error bars indicate the standard error of the mean.

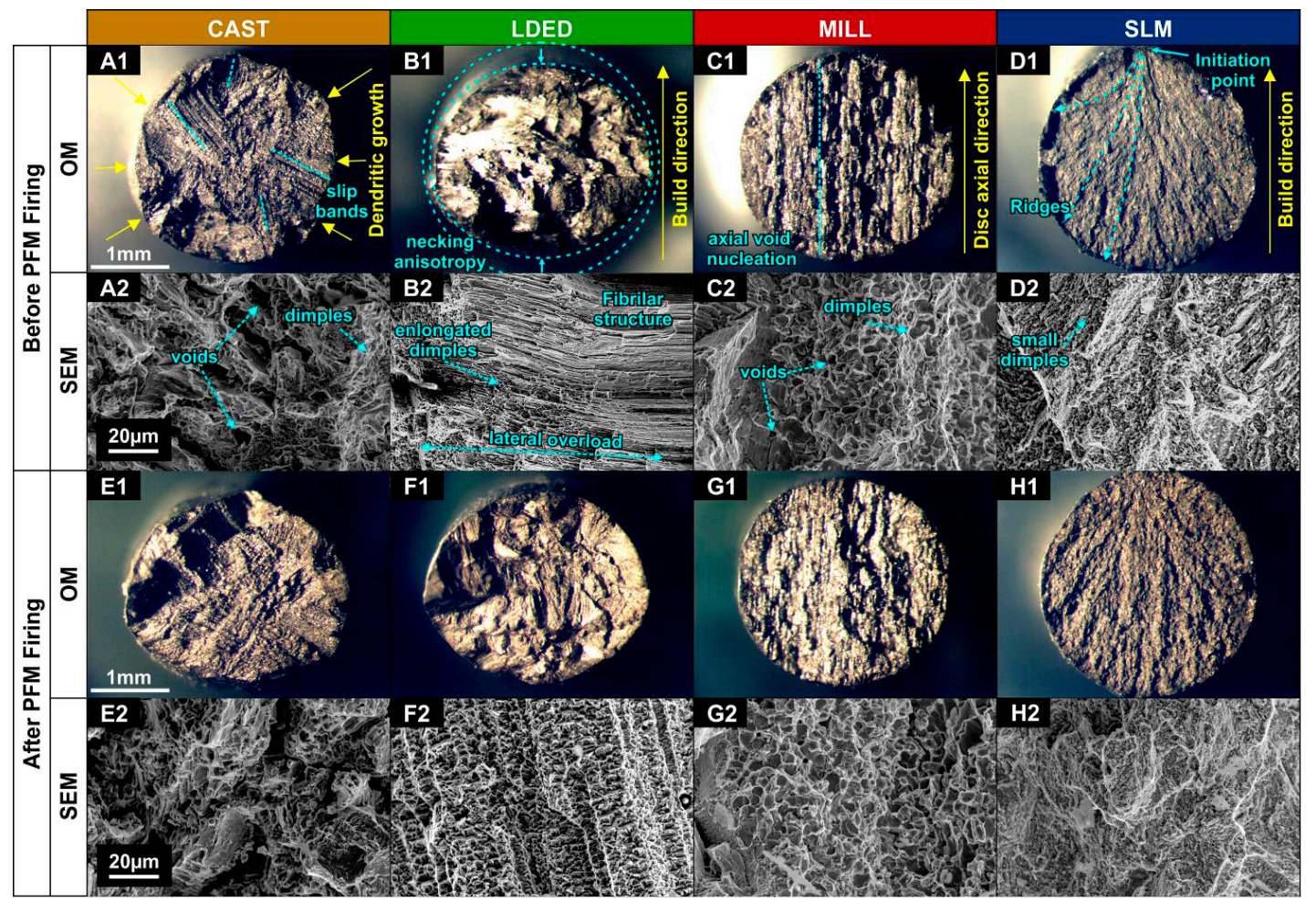

Figure 8. Fractographs showing the tensile samples breaking surface of each fabrication technique after fracture: CAST $(\mathbf{A}, \mathbf{E}), \operatorname{LDED}(\mathbf{B}, \mathbf{F}), \operatorname{MILL}(\mathbf{C}, \mathbf{G})$ and SLM $(\mathbf{D}, \mathbf{H})$. Originated from before $(\mathbf{A}-\mathbf{D})$ and after (E-H) PFM firing simulation samples, via optical microscopy (1) and SEM imaging (2). 


\subsection{Electrochemical Properties}

The electrochemical properties were analyzed by means of cyclic potentiodynamic polarization (CPDP). These tests were performed in an anodic direction until two decades of current density from the breakdown potential $\left(\mathrm{E}_{\mathrm{b}}\right)$. Then, the potential direction was reversed until the corrosion potential was reached. The tests were performed in aerated AS, in order to assess the corrosion behavior in the buccal medium, as well as in deaerated AS to assess the crevice corrosion in zones where the fluid has limited access, such as the gap between implant and abutment.

As can be seen in the CPDP curves (Figure 9), all alloys presented low current density at corrosion potential (Table 6), as well as negative hysteresis in both aerated (Figure 9A) and deaerated tests (Figure 9B). Considering also that the alloys' composition is mostly cobalt, the material corrosion speed was calculated for cobalt ions, in order to have more direct information about the durability of the metals (this corrosion speed can be observed in Figure 10A). The corrosion speed is reduced in all the cases, being under $4 \mu \mathrm{m} /$ year in all the cases. The breakdown potential (Eb) is similar (Figure 10B) in all the alloys, being $660 \mathrm{mV}$ for the aerated ones and $600 \mathrm{mV}$ for the deaerated ones.
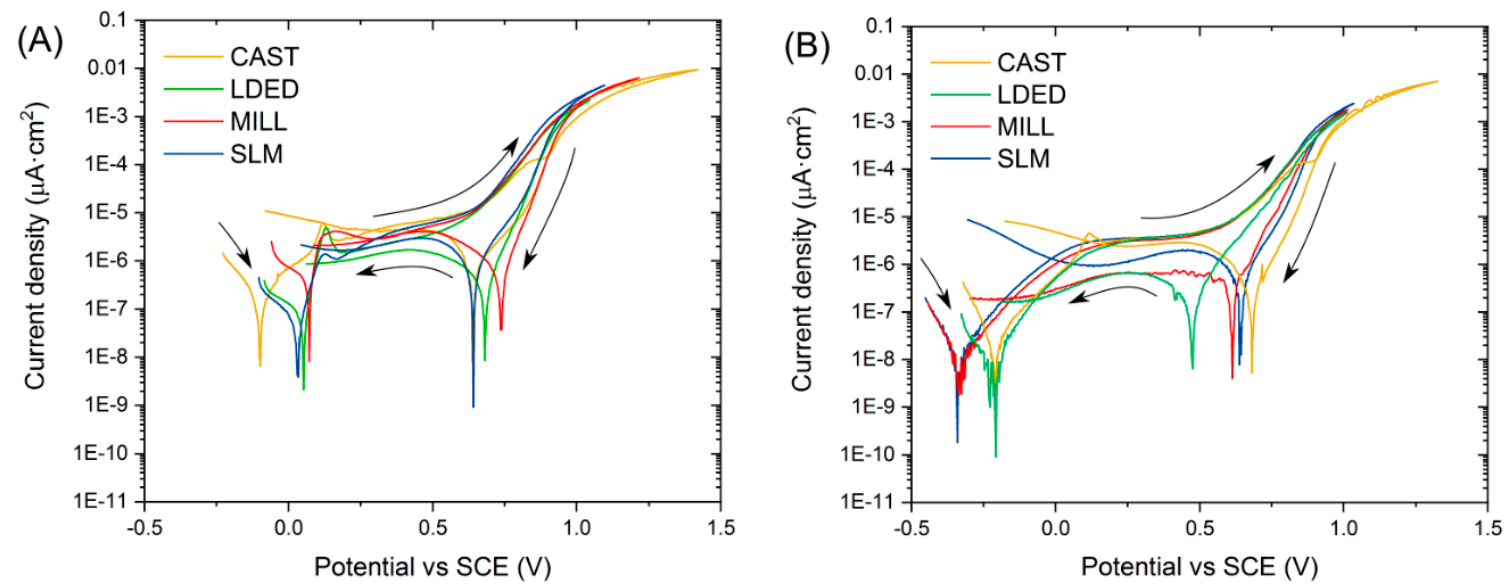

Figure 9. Representative cyclic potentiodynamic polarization curves of the different manufacturing techniques in aerated (A) and deaerated (B) artificial saliva (AS).

Table 6. Summary of the results of the cyclic potentiodynamic polarization (CPCD) tests.

\begin{tabular}{cccccc}
\hline $\begin{array}{c}\text { Electrolytic } \\
\text { Medium }\end{array}$ & $\begin{array}{c}\text { Manufacturing } \\
\text { Technique }\end{array}$ & $\begin{array}{c}\mathbf{E}_{\text {corr }} \\
(\mathbf{m V} \text { vs SCE) }\end{array}$ & $\begin{array}{c}\mathbf{i}_{\text {corr }} \\
\left(\mathbf{n} \mathbf{A} / \mathbf{c m}^{2}\right)\end{array}$ & $\begin{array}{c}\text { Corrosion Rate } \\
(\boldsymbol{\mu m} / \mathbf{y e a r})\end{array}$ & $\begin{array}{c}\mathbf{E}_{\mathbf{b}} \\
(\mathbf{m V} \mathbf{~ v s ~ S C E )})\end{array}$ \\
\hline Aerated & CAST & -88 & 122 & 1.3 & 667 \\
& LDED & 30 & 76 & 0.8 & 644 \\
& MILL & 82 & 365 & 4.0 & 652 \\
Deaerated & SLM & 36 & 107 & 1.2 & 666 \\
& CAST & -208 & 58 & 0.6 & 593 \\
& LDED & -328 & 11 & 0.1 & 650 \\
& MILL & -341 & 8 & 0.1 & 578 \\
\hline
\end{tabular}



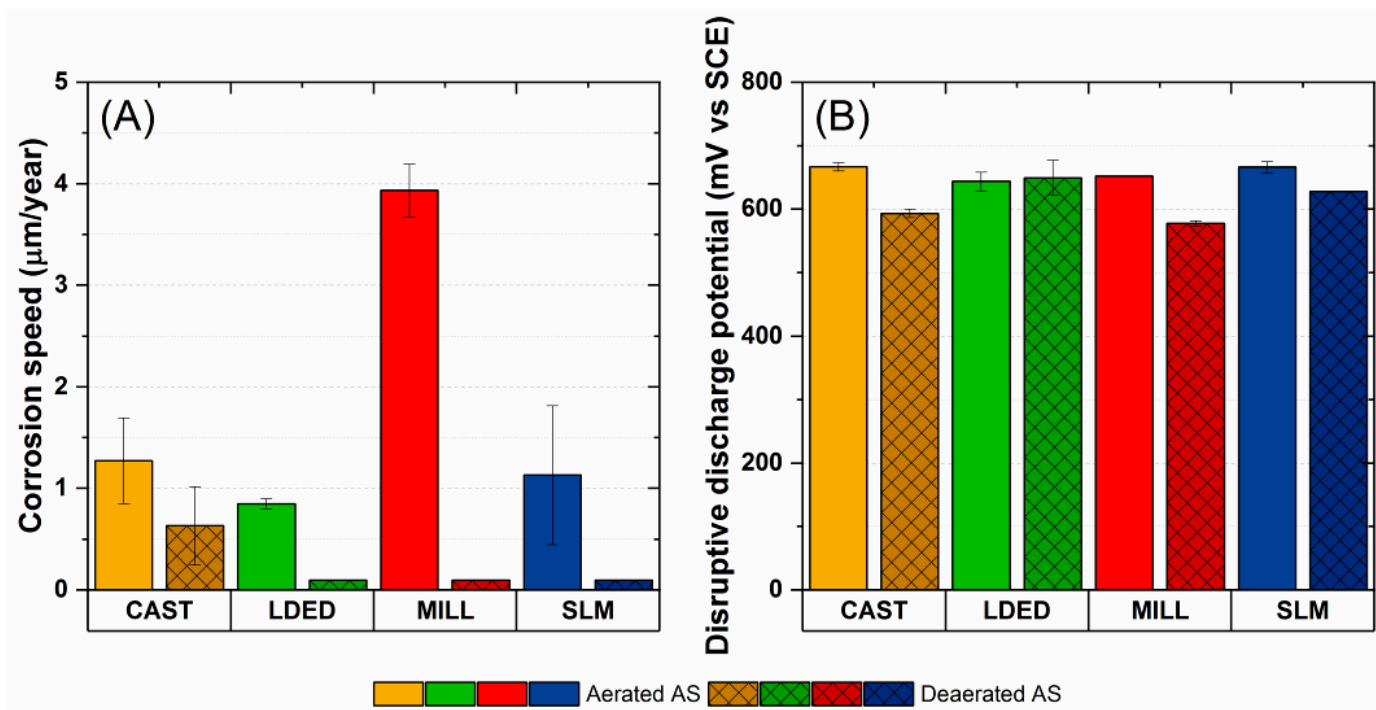

Figure 10. Equivalent corrosion speed (Co) (A) and disruptive discharge potential (B) of the different manufacturing techniques in aerated and deaerated AS. Error bars indicate the standard error of the mean.

\section{Discussion}

This study focused on the comparison of four different manufacturing techniques of PFM dental materials. Casting (CAST), milling (MILL), and selective laser melting (SLM) are currently employed in the prosthetic industry, while LDED is a novel technique which could be implemented in the production of these restorations. This comparison was performed through a multidisciplinary approach to combine the different ISO standards for dental materials as well as applying some additional tests. Therefore, the overall performance of the alloys was compiled by obtaining information from microstructural, mechanical, and electrochemical analyses; and then comparing them among themselves and with results obtained by previous researchers.

\subsection{Microstructure}

The microstructural analysis provides support for the characterization of the material, showing the different microstructures obtained between techniques, and suggesting the reasons behind different behaviors.

The CAST alloy possesses a typical coarse dendritic microstructure (Figure 2A), which exhibits a big segregation caused by its slow solidification rate, typical of dental casting manufacturing methods [12]. Dendritic grains are mainly $\gamma$-FCC phase (Figure 5A) with negligible presence of $\varepsilon$-HCP. This predominance of $\gamma$-FCC, in comparison with the other techniques, can be attributed to the presence of $\mathrm{Fe}(4 \%)$ and the high content of $\mathrm{W}(15 \%)$, which are known for being $\gamma$-stabilizers. In addition, the interdendritic segregations can be identified as $\sigma$ (zone 2, Figure 3 ) and laves phases (zone 3, Figure 3) [13].

The LDED alloy (Figure 2B) possessed a marked columnar structure, aligned with the building direction, composed by smaller columnar dendrites with submicrometric interdendritic segregations (Figure 3A,B). This columnar effect is caused by both directional thermal gradient and a consistent metallurgical bonding between layers generated during manufacturing [40]. Additionally, this texture alignment is in good agreement with previous works where it was suggested that preferred crystallographic orientation [41], or even epitaxial growth [42], can be achieved using the LDED technique. The phase composition has a predominance of $\gamma$-FCC columnar grains with a large mean size. However, as shown in Figure 2, these large grains are composed of aligned smaller dendrites inside the columnar matrix, indicating a much more refined microstructure. These aligned dendrites colonies have submicrometric interdendritic segregations due to the higher solidification rate. LDED has the 
smallest segregations of the four alloys, but its identification is probably the same as CAST alloys with $\sigma$ (zone 2, Figure 3) and laves phases (zone 3, Figure 3), this latter one not being discernible with SEM.

The MILL alloy (Figure 2C) presented a homogenous equiaxed grain structure with annealing twin boundaries and intergranular segregation. This microstructure is in accordance with continuous casting or hot rolling techniques [13], which are usually employed as disc manufacturing methods [43]. Phase composition of this alloy is a mixture of retained $\gamma$-FCC (77.73\%) and stable $\varepsilon$-HCP (22.27\%). MILL also showed a discernible orientation influence on the segregation patterns, distributed along the direction of manufacturing (Figure 2C). This alignment is caused by the directionality of the thermal gradients, and the segregation size is influenced by slower cooling rates that promote the segregation of both $\sigma$ (zone 2, Figure 3) and laves phases (zone 3, Figure 3).

The SLM alloy (Figure 2D) presented small grains with intergranular segregation as well as nearly negligible columnar dendritic structures inside the grains themselves. These smaller structures were uniformly distributed, with segregations in their interdendritic space, and were caused by the high thermal gradients and high cooling rates during manufacturing. This high cooling rate, combined with the small remelting depth of SLM between layers, induces the discontinuity of these grains [44], in contrast to LDED samples. The phase proportion of these grains is similar to MILL and LDED alloy, with retained $\gamma$-FCC and stable $\varepsilon$-HCP. The increased presence of Mo ( $\varepsilon$-stabilizer), and the reduced presence of $\mathrm{W}$ ( $\gamma$-stabilizer), should induce an increased proportion of $\varepsilon-\mathrm{HCP}$ [5]. However, this effect is probably compensated for with the fast cooling during manufacturing, since after the PFM process, the transformation to $\varepsilon-H C P$ is almost complete. It should be noted that LDED and SLM materials have similar grain and segregation growth behaviors. However, the final result is completely different due to the much higher thermal gradient and the reduction of the remelting area in the SLM technique. This difference is directly caused by the linear energy per pass given to the material of each technique [45].

XRD analyses verified that all the studied materials, even though they have slightly different compositions, have similar metallographic structures (Figure 4), in accordance with the previous literature $[8,9,46]$ of Co-Cr dental alloys. Additionally, there are also no significant differences among materials in the Young modulus, which is another indicator that the materials behave in a similar way. The differences among the studied materials can be attributed to the manufacturing technique. This is also exemplified by the preferential orientation (also denoted by the absence of the $\gamma$-FCC peak at $50.81^{\circ}$ ) observed in the samples produced by LDED and MILL processes, opposite to the non-oriented microstructure of the samples obtained by CAST and SLM.

\subsection{Mechanical Properties}

Regarding the mechanical properties, CAST seemed to have a similar behavior as LDED and MILL alloys, with no significant differences in yield strength, microhardness or Young modulus. However, a significant reduction in UTS (Figure 7B) and elongation after fracture (nearly halved, Figure 7E) was clear. These differences can be attributed to the evenly distributed big segregations, to the big grain size, as well as to internal casting porosities that influence the final performance [47]. Additionally, the fractographs verified the results. The CAST alloy showed a hybrid fracture surface (Figure 8A), with dimples and noticeable voids. The voids, caused by the big segregations, may induce the propagation of cracks by shear fracture along slip bands [48]. These slip bands can be clearly observed in CAST alloy (Figure 8A1,E1), verifying its reduced overall mechanical performance due to the increase in brittleness. Finally, PFM firing has no significant influence on CAST alloy. Before firings, the microstructure is already coarse, due to the slow cooling and solidification rates characteristic of the CAST method, hence, no evolution was observed.

LDED had an overall good mechanical behavior, being nearly the same as MILL alloy with no significant differences between yield strength, UTS, Young modulus, or elongation after fracture. It should be noted that the compliance with the ISO 22764 standard is complete, with even an elongation of more than seven times the required value after fracture. The fractographs also corroborate these 
results (Figure 8B), with a ductile rupture [49] and noticeable necking along an elongated dimple fracture surface, caused by substantial plastic deformation (15.57\%) [50]. Additionally, the LDED samples (Figure $8 \mathrm{~B}$ ) showed a higher reduction in section in the building direction, which implies some anisotropy in the mechanical properties in accordance to the microstructural results, where preferred orientation was identified. Cracks tend to initiate and propagate at grain boundaries, so plastic deformation will also occur along them [51]. Finally, through the PFM cycles, an increase in $\gamma$-FCC phase was denoted. This increment can be caused by the constant cooling rate during the furnace cycles in contraposition of a relatively constant temperature of the bulk material during the LDED process. However, this increase in $\gamma$-FCC phase is not detrimental and has no significant effect on the mechanical properties.

From a pure mechanical point of view, MILL material exhibits no significant differences in comparison with LDED. Both materials have similar mechanical behavior, with a ductile dimple fracture surface (LDED: 15.57\%, MILL: 15.34\%). However, the MILL material has bigger dimples and some voids probably caused by its bigger vertical segregations (Figure 2C1). These segregations could also lead to an anisotropy of crack propagation during fracture, and this could be responsible for the characteristic vertical jagged surface observed in macroscopic fractographs (Figure 8C1,C2). Before firings, the microstructure was cooled slowly, and the segregations had time to grow. It seems that with the firing cycles, the segregations grew and laves phase appeared in even more quantity. This increase could suggest the slight decrease in ductility seen in Figure 7E. However, mechanically, PFM firing had no significant influence on MILL alloy.

The yield strength along with the UTS of the SLM samples were higher than those corresponding to the other materials $(p<0.05)$, as can be seen in Figure 7A,B. However, this rise can be attributed to a material embrittlement, with only $3.6 \%$ of elongation and higher hardness. This brittleness is caused by two factors. The first is the angle of the tensile load with regard to the building direction. This angle has a great influence on mechanical properties. Previous studies have demonstrated that the elongation after fracture of the specimens tested, with building direction parallel to tensile direction, change dramatically in comparison to the ones tested perpendicularly (from $4.7 \%$ with $90^{\circ}$ to $10.7 \%$ at $0^{\circ}$ [52]). This anisotropy is caused mainly by the alignment of the segregations, because when the material is subjected to tensile stress perpendicular to the columnar grain direction, dislocations and cracks slip are promoted along the columnar grain direction [44]. The second effect is the characteristic residual stresses present in parts that are manufactured by SLM [53]. This fact means that SLM manufacturers recommend an annealing process in the furnace for releasing these internal stresses [54]. In the fractographs the brittle behavior is verified. The SLM samples showed a flat perpendicular cleavage rupture [55,56] (Figure 8D), typical of brittle materials [49]. Finally, in the SLM materials, the PFM firings had noticeable effect on the microstructure, where an almost complete transformation of $\gamma$-FCC into $\varepsilon$-HCP was observed. This result also matches with those of the LDED and MILL samples, where the slower cooling rates of the manufacturing technique had a $\gamma$-FCC stabilization effect of the veneering samples. However, in the SLM technique, the solidification rates during the manufacturing method were much faster than the veneering cooling rates and, with the presence of Mo ( $\varepsilon$-stabilizer), the conversion to $\varepsilon$-HCP was practically complete after the PFM firings. This phase change also explains the reduction of ductility after the firings, due to the suppression of the beneficial effects of the $\gamma$-FCC phase in the mechanical properties of Cobalt based alloys [5].

Hardness has a strong influence on tool life during machining [57]. The LDED, MILL, and CAST specimens presented similar hardness, therefore similar machining behavior is expected. However, the SLM hardness (Figure 7G) was significantly higher $(p<0.05)$ and implies decreased tool life.

All these mechanical parameters compared independently, as is indicated in the ISO 22764, do not give an adequate overview of the real behavior of the alloys in real situations. That is why, to compare these materials quantitatively, the analysis of the modulus of toughness was performed. The toughness can be defined as the energy per volume absorbed by the material before breaking, and it can be calculated through the integration of the area under the stress-strain curve [58]. Through this method, 
the analysis of the toughness (Figure 7D) shows that the materials generated by LDED and MILL techniques clearly behaved better, absorbing nearly twice the energy until fracture. This better behavior was achieved thanks to the UTS combined with a wide strain (Figure 7E). The CAST material, as can be seen in Figure 7E, performed worse. It kept the same tendency as LDED and MILL at the start, but broke at low strain. On the other hand, the SLM specimens broke at high UTS but with very limited strain, the energy absorbed being notably smaller in comparison to the ones absorbed by LDED and MILL alloys $(p<0.05)$.

Toughness is important due to the fact that when veneering processes are applied, ceramic materials generate contraction stresses during PFM firing processes. These stresses can produce an undesirable fracture. Therefore, the absorption of this energy is of great importance in order to reach a good balance between the deformation of the material and its resistance for its working life.

The segregations' influence should be highlighted in these dental Co-Cr alloys. The size of these segregations is directly affected by the cooling rates [46], and the direction of, or alignment of, them is the cause of the anisotropy in alloys [44]. That is why dislocations and cracks slip along these segregations are promoted when the material is subjected to tensile stresses perpendicular to the columnar grain direction [51]. These segregations also provoke a reduction of the chemical homogeneity of the material that could lead to intergranular corrosion [59], which is one common factor of triggering fatigue fracture in hip [60] and femoral stems [61] made of Co-Cr alloys.

\subsection{Electrochemical Properties}

The electrochemical properties of the materials obtained by the four techniques were quite similar, with a corrosion rate of under 4 microns per year. The difference between the results obtained under aerated and deaerated medium of $60 \mathrm{mV}$ (Figure 9B) can be attributed to the difference in the electrolytic medium, which changes the $\mathrm{pH}$ from 7.2 to 8.2 in the deaerated ones, caused by the deaeration process and decarbonation of the electrolyte.

The breakdown potential also showed an oxidation of the passive layer of the material. The negative hysteresis (Figure 9) demonstrates that no pitting corrosion was formed [62]. Furthermore, the anodic to cathodic potential in the reverse direction was at higher potential than the corrosion potential, which means that the generated new oxide layer was stable [63]. Finally, Figure 10A shows that even when the corrosion speed of all materials was relatively lower in the aerated medium, in deaerated medium, it was lower, so the performance against crevice corrosion was better [64].

\section{Conclusions}

Four different dental restorative Co-Cr manufacturing techniques were investigated in order to compare their metallographic, mechanical, and electrochemical behavior:

- Co-Cr dental alloys manufactured via casting, LDED, milling, and SLM techniques present evident differences in their mechanical properties.

- The electrochemical performance of all Co-Cr alloys was similar, with high resistance to corrosion in artificial saliva in both aerated and deaerated media.

- Microstructure has an important impact in mechanical behavior of dental Co-Cr alloys. The size and spatial disposition of segregations have a remarkable influence on mechanical properties affecting fracture mechanisms.

- Standards have an important role in assessing the quality of the materials employed in the industry, but care has to be taken because of their limitations, and some important properties may not be evaluated.

- The modulus of toughness is an important property in order to evaluate the overall performance of the materials. LDED and milling were the best techniques in this study, with better results in this characteristic. 
- LDED is an additive manufacturing technique that can be implemented in the restorative dental industry with high overall performance. This manufacturing process can compete directly with the best quality techniques, and taking the best part of each of them, mechanical properties from milling disk, and freeform generation from SLM processes.

Author Contributions: F.G.-B. and J.P. designed the work. Ó.B. and F.A.-G. performed all LDED tests. F.L. and J.d.V. analyzed the microstructure of all samples. R.C. and A.B. carried out the evaluation of the mechanical properties of the samples. A.R. and A.B. performed microhardness tests. F.G.-B. and Ó.B. obtained the casting samples. Ó.B. and F.A.-G. obtained the CAD/CAM milling samples. J.d.V. and A.R. were responsible for the SLM samples. Ó.B. and R.C. performed all corrosion tests. Ó.B., F.L. and J.P. contributed to write the manuscript with the input from all other authors. All authors have read and agreed to the published version of the manuscript.

Funding: This work was partially supported by the EU research project Bluehuman (EAPA_151/2016 Interreg Atlantic Area), Government of Spain [CLADDENT project_CDTI, RTI2018-095490-J-I00 (MCIU/AEI/FEDER, UE)], and by Xunta de Galicia (ED431C 2019/23, ED481D 2017/010, ED481B 2016/047-0).

Acknowledgments: The technical staff from CACTI (University of Vigo), SAI (University of A Coruña) and AGACYP (University of Vigo) is gratefully acknowledged.

Conflicts of Interest: The authors declare no conflict of interest.

\section{Appendix A}

Table A1. Summary of the significant differences $(p<0.05)$ of the mechanical properties results.

\begin{tabular}{|c|c|c|c|c|c|c|c|}
\hline \multicolumn{2}{|c|}{ Materials Compared } & \multicolumn{6}{|c|}{ Mechanical Properties Evaluated } \\
\hline Material 1 & Material 2 & $\begin{array}{c}\text { Yield } \\
\text { Strength } \\
0.2 \% \\
(\mathrm{MPa})\end{array}$ & $\begin{array}{l}\text { Ultimate } \\
\text { Tensile } \\
\text { Strength } \\
\text { (MPa) }\end{array}$ & $\begin{array}{l}\text { Young } \\
\text { Modulus } \\
\text { (GPa) }\end{array}$ & $\begin{array}{c}\begin{array}{c}\text { Modulus } \\
\text { of } \\
\text { Toughness } \\
\left(\mathbf{M J} / \mathbf{m}^{3}\right)\end{array}\end{array}$ & $\begin{array}{c}\text { Enlongation } \\
\text { After } \\
\text { Fracture } \\
(\%)\end{array}$ & $\begin{array}{c}\text { Microhardness } \\
\text { (HV) }\end{array}$ \\
\hline $\begin{array}{l}\text { CAST } \\
\text { before }\end{array}$ & CAST after & - & - & - & - & - & - \\
\hline $\begin{array}{l}\text { CAST } \\
\text { before }\end{array}$ & $\begin{array}{l}\text { LDED } \\
\text { before }\end{array}$ & - & Yes & - & Yes & Yes & Yes \\
\hline $\begin{array}{l}\text { CAST } \\
\text { before }\end{array}$ & $\begin{array}{l}\text { LDED } \\
\text { after }\end{array}$ & - & Yes & - & Yes & Yes & Yes \\
\hline $\begin{array}{l}\text { CAST } \\
\text { before }\end{array}$ & $\begin{array}{l}\text { MILL } \\
\text { before }\end{array}$ & - & Yes & - & Yes & Yes & - \\
\hline $\begin{array}{l}\text { CAST } \\
\text { before }\end{array}$ & MILL after & - & Yes & - & Yes & Yes & - \\
\hline $\begin{array}{l}\text { CAST } \\
\text { before }\end{array}$ & $\begin{array}{c}\text { SLM } \\
\text { before }\end{array}$ & Yes & Yes & - & - & Yes & Yes \\
\hline $\begin{array}{l}\text { CAST } \\
\text { before }\end{array}$ & SLM after & Yes & Yes & - & - & Yes & Yes \\
\hline CAST after & $\begin{array}{l}\text { LDED } \\
\text { before }\end{array}$ & - & Yes & - & Yes & Yes & - \\
\hline CAST after & $\begin{array}{l}\text { LDED } \\
\text { after }\end{array}$ & - & Yes & - & Yes & Yes & - \\
\hline CAST after & $\begin{array}{l}\text { MILL } \\
\text { before }\end{array}$ & - & Yes & - & Yes & Yes & - \\
\hline
\end{tabular}


Table A1. Cont.

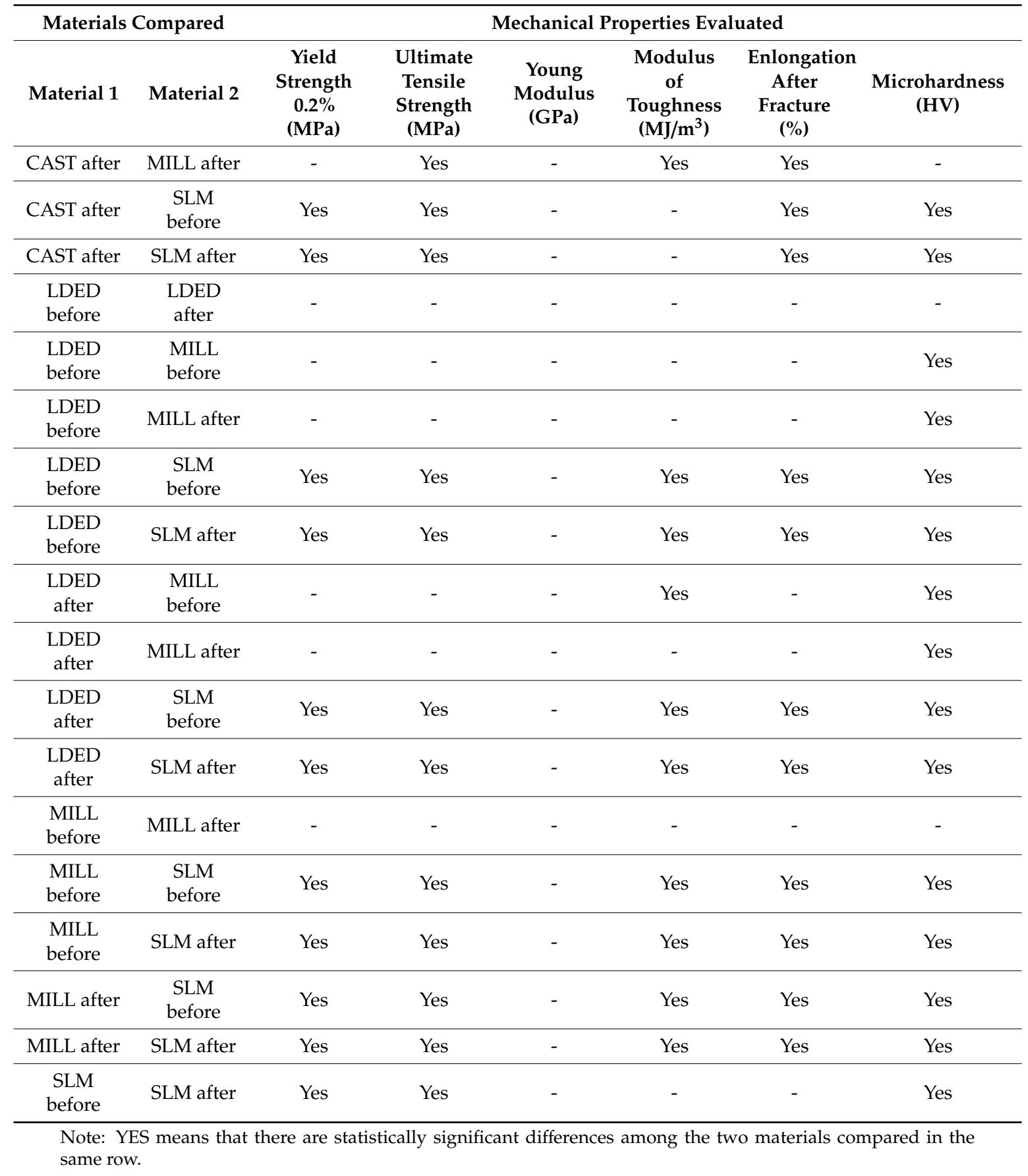

\section{References}

1. Knosp, H.; Holliday, R.J.; Corti, C.W. Gold in dentistry: Alloys, uses and performance. Gold Bull. 2003, 36, 93-102. [CrossRef]

2. Denkhaus, E.; Salnikow, K. Nickel essentiality, toxicity, and carcinogenicity. Crit. Rev. Oncol. 2002, 42, 35-56. [CrossRef]

3. Steinemann, S.; Perren, S. Titanium alloys as metallic biomaterials. Titan. Sci. Technol. 1984, 2, 1327-1334.

4. Helsen, J.A.; Breme, J. Metals As Biomaterials; Wiley-VCH: Chichester, UK, 1998; ISBN 978-0-471-96935-8.

5. Davis, J.R. ASM Specialty Handbook: Nickel, Cobalt, and Their Alloys; ASM International: Materials Park, $\mathrm{OH}$, USA, 2001; Volume 38, ISBN 978-0-87170-685-0. 
6. Mani, A.; Salinas-Rodriguez, A.; Lopez, H. Deformation induced FCC to HCP transformation in a Co-27Cr-5Mo-0.05C alloy. Mater. Sci. Eng. A 2011, 528, 3037-3043. [CrossRef]

7. Tian, L.-Y.; Lizárraga, R.; Larsson, H.; Holmström, E.; Vitos, L. A first principles study of the stacking fault energies for fcc Co-based binary alloys. Acta Mater. 2017, 136, 215-223. [CrossRef]

8. Li, K.C.; Prior, D.J.; Waddell, J.N.; Swain, M. Comparison of the microstructure and phase stability of as-cast, CAD/CAM and powder metallurgy manufactured Co-Cr dental alloys. Dent. Mater. 2015, 31, e306-e315. [CrossRef]

9. Al Jabbari, Y.S.; Koutsoukis, T.; Barmpagadaki, X.; Zinelis, S. Metallurgical and interfacial characterization of PFM Co-Cr dental alloys fabricated via casting, milling or selective laser melting. Dent. Mater. 2014, 30, e79-e88. [CrossRef]

10. Espevik, S. Corrosion of base metal alloys in vitro. Acta Odontol. Scand. 1978, 36, 113-116. [CrossRef]

11. Karaali, A.; Mirouh, K.; Hamamda, S.; Guiraldenq, P. Microstructural study of tungsten influence on Co-Cr alloys. Mater. Sci. Eng. A 2005, 390, 255-259. [CrossRef]

12. Yamanaka, K.; Mori, M.; Chiba, A. Assessment of precipitation behavior in dental castings of a Co-Cr-Mo alloy. J. Mech. Behav. Biomed. Mater. 2015, 50, 268-276. [CrossRef]

13. Yamanaka, K.; Mori, M.; Kuramoto, K.; Chiba, A. Development of new Co-Cr-W-based biomedical alloys: Effects of microalloying and thermomechanical processing on microstructures and mechanical properties. Mater. Des. 2014, 55, 987-998. [CrossRef]

14. Ramírez, L.; Castro, M.; Mendez, M.; Lacaze, J.; Herrera, M.; Lesoult, G. Precipitation path of secondary phases during solidification of the Co- 25.5\%Cr- 5.5\%Mo\&ndash; 0.26\% C alloy. Scr. Mater. 2002, 47, 811-816. [CrossRef]

15. Yamanaka, K.; Mori, M.; Chiba, A. Developing high strength and ductility in biomedical Co-Cr cast alloys by simultaneous doping with nitrogen and carbon. Acta Biomater. 2016, 31, 435-447. [CrossRef] [PubMed]

16. Padrós, R.; Punset, M.; Molmeneu, M.; Velasco, A.B.; Herrero-Climent, M.; Rupérez, E.; Gil, F.J. Mechanical properties of $\mathrm{CoCr}$ dental-prosthesis restorations made by three manufacturing processes. influence of the microstructure and topography. Metals 2020, 10, 788. [CrossRef]

17. Xin, X.-Z.; Chen, J.; Xiang, N.; Gong, Y.; Wei, B. Surface characteristics and corrosion properties of selective laser melted Co-Cr dental alloy after porcelain firing. Dent. Mater. 2014, 30, 263-270. [CrossRef]

18. Padrós, R.; Tarrida, L.G.; Herrero-Climent, M.; Punset, M.; Gil, F.J. Corrosion resistance and ion release of dental prosthesis of CoCr obtained by CAD-CAM milling, casting and laser sintering. Metals 2020, 10, 827. [CrossRef]

19. Karpuschewski, B.; Pieper, H.J.; Krause, M.; Döring, J. CoCr is Not the Same: CoCr-Blanks for Dental Machining. In Future Trends in Production Engineering; Springer Science and Business Media LLC: Berlin, Germany, 2012; pp. 261-274.

20. Li, J.; Chen, C.; Liao, J.; Liu, L.; Ye, X.; Lin, S.; Ye, J.-T. Bond strengths of porcelain to cobalt-chromium alloys made by casting, milling, and selective laser melting. J. Prosthet. Dent. 2016, 118, 69-75. [CrossRef] [PubMed]

21. Zangeneh, S.; Lashgari, H.R.; Alsaadi, S.; Mohamad-Moradi, S.; Saghafi, M. The effect of cyclic solution heat treatment on the martensitic phase transformation and grain refinement of Co-Cr-Mo dental alloy. Metals 2020, 10, 861. [CrossRef]

22. Yap, C.Y.; Chua, C.K.; Dong, Z.; Liu, Z.H.; Zhang, D.Q.; Loh, L.E.; Sing, S.L. Review of selective laser melting: Materials and applications. Appl. Phys. Rev. 2015, 2, 041101. [CrossRef]

23. Koutsoukis, T.; Zinelis, S.; Eliades, G.; Al-Wazzan, K.; Al Rifaiy, M.; Al Jabbari, Y.S. Selective laser melting technique of Co-Cr dental alloys: A Review of structure and properties and comparative analysis with other available techniques. J. Prosthodont. 2015, 24, 303-312. [CrossRef]

24. Prashanth, K.G.; Kolla, S.; Eckert, J. Additive manufacturing processes: Selective laser melting, electron beam melting and binder jetting-selection guidelines. Materials 2017, 10, 672. [CrossRef]

25. Fortunato, A.; Lulaj, A.; Melkote, S.; Liverani, E.; Ascari, A.; Umbrello, D. Milling of maraging steel components produced by selective laser melting. Int. J. Adv. Manuf. Technol. 2017, 94, 1895-1902. [CrossRef]

26. Sameni, M.K.; Toyserkani, E.; Khajepour, A. Fuzzy Model and Compact Fuzzy Model Identification of Laser Cladding Process; Laser Institute of America: Orlando, FL, USA, 2004; Volume 2004, p. 604.

27. Zhong, C.; Gasser, A.; Schopphoven, T.; Poprawe, R. Experimental study of porosity reduction in high deposition-rate laser material deposition. Opt. Laser Technol. 2015, 75, 87-92. [CrossRef] 
28. Arias-González, F.; Del Val, J.; Comesaña, R.; Penide, J.; Lusquiños, F.; Quintero, F.; Riveiro, A.; Boutinguiza, M.; Pou, J.; Penide, J. Fiber laser cladding of nickel-based alloy on cast iron. Appl. Surf. Sci. 2016, 374, 197-205. [CrossRef]

29. Amado, J.; Rodríguez, A.; Montero, J.; Tobar, M.; Yáñez, A. A comparison of laser deposition of commercially pure titanium using gas atomized or Ti sponge powders. Surf. Coatings Technol. 2019, 374, 253-263. [CrossRef]

30. Ram, G.D.J.; Esplin, C.K.; Stucker, B.E. Microstructure and wear properties of LENS ${ }^{\circledR}$ deposited medical grade CoCrMo. J. Mater. Sci. Mater. Electron. 2007, 19, 2105-2111. [CrossRef]

31. Del Val, J.; Comesaña, R.; Riveiro, A.; Lusquiños, F.; Quintero, F.; Boutinguiza, M.; Pou, J. Laser direct writing of Co-superalloy lines for micro-fabrication applications. Surf. Coatings Technol. 2018, 345, 76-88. [CrossRef]

32. Schmidt, M.; Merklein, M.; Bourell, D.; Dimitrov, D.; Hausotte, T.; Wegener, K.; Overmeyer, L.; Vollertsen, F.; Levy, G.N. Laser based additive manufacturing in industry and academia. CIRP Ann. 2017, 66, 561-583. [CrossRef]

33. Comesaña, R.; Lusquiños, F.; Del Val, J.; Quintero, F.; Riveiro, A.; Boutinguiza, M.; Jones, J.R.; Hill, R.G.; Pou, J. Toward smart implant synthesis: Bonding bioceramics of different resorbability to match bone growth rates. Sci. Rep. 2015, 5, 10677. [CrossRef]

34. Shamsaei, N.; Yadollahi, A.; Bian, L.; Thompson, S.M. An overview of direct laser deposition for additive manufacturing; Part II: Mechanical behavior, process parameter optimization and control. Addit. Manuf. 2015, 8, 12-35. [CrossRef]

35. Huang, Y.; Ansari, M.; Asgari, H.; Farshidianfar, M.H.; Sarker, D.; Khamesee, M.B.; Toyserkani, E. Rapid prediction of real-time thermal characteristics, solidification parameters and microstructure in laser directed energy deposition (powder-fed additive manufacturing). J. Mater. Process. Technol. 2019, 274, 116286. [CrossRef]

36. Bai, Y.; Chaudhari, A.; Wang, H. Investigation on the microstructure and machinability of ASTM A131 steel manufactured by directed energy deposition. J. Mater. Process. Technol. 2020, 276, 116410. [CrossRef]

37. Mantrala, K.M.; Das, M.; Balla, V.K.; Rao, C.S.; Rao, V.K. Laser-deposited CoCrMo alloy: Microstructure, wear, and electrochemical properties. J. Mater. Res. 2014, 29, 2021-2027. [CrossRef]

38. España, F.A.; Balla, V.K.; Bose, S.; Bandyopadhyay, A. design and fabrication of CoCrMo alloy based novel structures for load bearing implants using laser engineered net shaping. Mater. Sci. Eng. C 2010, 30, 50-57. [CrossRef]

39. Smith, E. The nucleation and growth of cleavage microcracks in mild steel. Phys. Basis Yield Fract. Conf. Proc. 1966, 1966, 36-46.

40. Akram, J.; Chalavadi, P.; Pal, D.; Stucker, B. Understanding grain evolution in additive manufacturing through modeling. Addit. Manuf. 2018, 21, 255-268. [CrossRef]

41. Arias-González, F.; Del Val, J.; Comesaña, R.; Penide, J.; Lusquiños, F.; Quintero, F.; Riveiro, A.; Boutinguiza, M.; Gil, F.J.; Pou, J. Microstructure and crystallographic texture of pure titanium parts generated by laser additive manufacturing. Met. Mater. Int. 2018, 24, 231-239. [CrossRef]

42. Shishkovsky, I.V.; Missemer, F.; Smurov, I. Metal matrix composites with ternary intermetallic inclusions fabricated by laser direct energy deposition. Compos. Struct. 2018, 183, 663-670. [CrossRef]

43. Reclaru, L.; Ardelean, L.C. Alternative Processing Techniques for CoCr Dental Alloys; Elsevier BV: Amsterdam, The Netherlands, 2019; pp. 1-15.

44. Xiang, D.; Wang, P.; Tan, X.; Chandra, S.; Wang, C.; Nai, M.; Tor, S.; Liu, W.; Liu, E. Anisotropic microstructure and mechanical properties of additively manufactured Co-Cr-Mo alloy using selective electron beam melting for orthopedic implants. Mater. Sci. Eng. A 2019, 765, 138270. [CrossRef]

45. Zhao, Y.; Koizumi, Y.; Aoyagi, K.; Wei, D.; Yamanaka, K.; Chiba, A. Comprehensive study on mechanisms for grain morphology evolution and texture development in powder bed fusion with electron beam of Co-Cr-Mo alloy. Materials 2019, 6, 100346. [CrossRef]

46. Zhou, Y.; Li, N.; Yan, J.; Zeng, Q. Comparative analysis of the microstructures and mechanical properties of Co-Cr dental alloys fabricated by different methods. J. Prosthet. Dent. 2018, 120, 617-623. [CrossRef]

47. Al Jabbari, Y.S.; Barmpagadaki, X.; Psarris, I.; Zinelis, S. Microstructural, mechanical, ionic release and tarnish resistance characterization of porcelain fused to metal $\mathrm{Co}-\mathrm{Cr}$ alloys manufactured via casting and three different CAD/CAM techniques. J. Prosthodont. Res. 2019, 63, 150-156. [CrossRef] [PubMed]

48. Knott, J. Micro-Mechanisms of Fracture and The Fracture Toughness of Engineering Alloys. In Advances in Research on the Strength and Fracture of Materials; Elsevier BV: Amsterdam, The Netherlands, 1978; pp. 61-92. 
49. ASM Handbook Committee Fractography; ASM International: Materials Park, OH, USA, 1987; ISBN 978-1-62708-181-8.

50. Brandon, D.; Kaplan, W.D. Microstructural Characterization of Materials; Wiley: Chichester, UK, 2008.

51. Sun, S.-H.; Koizumi, Y.; Kurosu, S.; Li, Y.; Matsumoto, H.; Chiba, A. Build direction dependence of microstructure and high-temperature tensile property of Co-Cr-Mo alloy fabricated by electron beam melting. Acta Mater. 2014, 64, 154-168. [CrossRef]

52. Takaichi, A.; Suyalatu; Nakamoto, T.; Joko, N.; Nomura, N.; Tsutsumi, Y.; Migita, S.; Doi, H.; Kurosu, S.; Chiba, A.; et al. Microstructures and mechanical properties of Co- 29Cr- $6 \mathrm{Mo}$ alloy fabricated by selective laser melting process for dental applications. J. Mech. Behav. Biomed. Mater. 2013, 21, 67-76. [CrossRef]

53. Dikova, T. Properties of Co-Cr Dental Alloys Fabricated Using Additive Technologies. In Biomaterials in Regenerative Medicine; IntechOpen: London, UK, 2018; Volume I, p. 13.

54. Ayyıldız, S.; Soylu, E.H.; Ide, S.; Kılıç, S.; Sipahi, C.; Pişkin, B.; Gokce, H.S. Annealing of Co-Cr dental alloy: Effects on nanostructure and Rockwell hardness. J. Adv. Prosthodont. 2013, 5, 471-478. [CrossRef]

55. Qian, B.; Saeidi, K.; Kvetková, L.; Lofaj, F.; Xiao, C.; Shen, Z. Defects-tolerant Co-Cr-Mo dental alloys prepared by selective laser melting. Dent. Mater. 2015, 31, 1435-1444. [CrossRef]

56. Lee, H.W.; Jung, K.-H.; Hwang, S.-K.; Kang, S.-H.; Kim, D.-K. Microstructure and mechanical anisotropy of CoCrW alloy processed by selective laser melting. Mater. Sci. Eng. A 2019, 749, 65-73. [CrossRef]

57. Kalpakjian, S.; Schmid, S.R. Manufacturing Engineering, 6th ed.; Pearson Prentice Hall: Upper Saddle River, NJ, USA, 2009; ISBN 978-9810681449.

58. Tobolski, E.L.; Fee, A. ASM Handbook: Mechanical Testing and Evaluation; ASM International: Materials Park, OH, USA, 2000; Volume 8, ISBN 0-87170-389-0.

59. Wang, Q.; Eltit, F.; Wang, R. Corrosion of Orthopedic Implants. In Encyclopedia of Biomedical Engineering; Elsevier BV: Amsterdam, The Netherlands, 2019; pp. 65-85.

60. Norman, P.; Iyengar, S.; Svensson, I.; Flivik, G. Fatigue fracture in dual modular revision total hip arthroplasty stems. J. Arthroplast. 2014, 29, 850-855. [CrossRef]

61. Wang, Q.; Parry, M.; Masri, A.B.; Duncan, C.; Wang, R. Failure mechanisms in CoCrMo modular femoral stems for revision total hip arthroplasty. J. Biomed. Mater. Res. Part B Appl. Biomater. 2016, 105, 1525-1535. [CrossRef]

62. Esmailzadeh, S.; Aliofkhazraei, M.; Sarlak, H. Interpretation of cyclic potentiodynamic polarization test results for study of corrosion behavior of metals: A review. Prot. Met. Phys. Chem. Surfaces 2018, 54, 976-989. [CrossRef]

63. Diaz, I.; Martinez-Lerma, J.; Montoya, R.; Llorente, I.; Escudero, M.; Garcia-Alonso, M.C. Study of overall and local electrochemical responses of oxide films grown on $\mathrm{CoCr}$ alloy under biological environments. Bioelectrochemistry 2017, 115, 1-10. [CrossRef] [PubMed]

64. Schweitzer, P.A. Fundamentals of Corrosion-Mechanisms, Causes, and Preventative Methods; CRC Press: Boca Raton, FL, USA, 2013; Volume 53, ISBN 9788578110796.

(C) 2020 by the authors. Licensee MDPI, Basel, Switzerland. This article is an open access article distributed under the terms and conditions of the Creative Commons Attribution (CC BY) license (http://creativecommons.org/licenses/by/4.0/). 